\title{
1 Transport Properties of Oleuropein Through Nanofiltration Membranes
}

2

3 Ilyes Dammak ${ }^{a, c}$, Marcos A. Neves ${ }^{b, c}$, Hiroshi Nabetani ${ }^{c}$, Hiroko Isoda ${ }^{b}$, Sami

$4 \quad$ Sayadi $^{d}$, Mitsutoshi Nakajima ${ }^{b, c, *}$

$5 \quad{ }^{a}$ Graduate School of Life and Environmental Sciences, University of Tsukuba, Ibaraki 305-8572,

6 Japan

$7 \quad{ }^{b}$ Faculty of Life and Environmental Sciences, University of Tsukuba, Ibaraki 305-8572, Japan

$8 \quad{ }^{c}$ National Food Research Institute, NARO, Tsukuba, Ibaraki 305-8642, Japan

$9{ }^{d}$ Environmental Bioprocess Laboratory, Center of Biotechnology of Sfax B. P. 3038, Sfax, Tunisia

$10 \quad{ }^{*}$ Corresponding author: Tel.: +81 029853 3981; fax: +81 0298535776.

11 E-mail address: nakajima.m.fu@u.tsukuba.ac.jp (M. Nakajima)

12 


\section{$1 \quad$ ABSTRACT}

2 The present work investigates the effect of feed concentration and magnitudes of applied

3 pressure of olive-extracted oleuropein on permeate flux and membrane transport properties

4 through concentration polarization in a nanofiltration (NF) membrane. The filtration of

5 oleuropein model solution by an NF membrane using different feed concentrations $(0.3,0.9$,

6 or $2.7 \mathrm{~kg} \mathrm{~m}^{-3}$ ) enables the correlation of a transport model, comprised of concentration

7 polarization and osmotic pressure models, to membrane retention performance, evaluated

8 using the Spiegler-Kedem model. Moreover, osmotic pressure was observed and interpreted

9 using the van't Hoff equation at different levels of feed concentration and applied pressure.

10 Transport parameters (reflection coefficient, water and oleuropein permeability, and mass transfer coefficient) were correlated with experiment values by developing a mathematical model that reflects the flux decline by increasing osmotic pressure. 


\section{INTRODUCTION}

Polyphenols are complex mixtures that have rich structural variety and a wide range of biological activities, as evidenced by their antioxidant and health-enhancing properties (AlAzzawie \& Alhamdani, 2006). Recent increasing interest has focused on olive polyphenol recovery, which correlates well with related physicochemical and biochemical processes adopted in recovering polyphenols from olive trees (Gutierrez-Rosales et al., 2012).

Oleuropein, which is an ester of hydroxytyrosol and elenolic acid glucoside (Fig. 1), has gained interest as a natural food antioxidant (Takaç \& Karakaya, 2009). Oleuropein is the most abundant polyphenol in olive leaves (60 to $90 \mathrm{mg} / \mathrm{g}$ dry weight) (Le Tutour \& Guedon, 1992; Servili et $a l ., 1999)$. The health-promoting properties of oleuropein have been widely investigated (Al-Azzawie \& Alhamdani, 2006; Ranalli et al., 2006; Sheu et al., 2004). Consequently, there has been much interest in developing new extraction and separation techniques to recover oleuropein from olive residue (Agalias et al., 2007; Garcia-Castello et al., 2010; Malik \& Bradford, 2008).

Several techniques used individually or in combination have been adopted to recover olive polyphenols. These techniques are mainly extraction, centrifugation, and chromatographic procedures. In those processes, however, complexities result not only from their cost and operational characteristics, but also from the toxicity and flammability of the organic solvent that is required in large amounts (Takaç \& Karakaya, 2009).

Nanofiltration (NF) is an advanced membrane separation process in the liquid phase. It uses membranes with pore sizes within nanometer range to meet industrial needs in the area of small molecules $(<1 \mathrm{kDa})$ and ion separation (Saliha et al., 2009). Energy requirements are potentially much lower for NF than for conventional separation processes, leading to significant cost savings. Separation by NF membranes occurs primarily due to size exclusion and electrostatic interactions (i.e., the Donnan effect) (Yaroshchuk, 2008). For uncharged 
1 molecules, sieving or size exclusion is the major factor responsible for separation (Qi et al.,

2 2011). However, the mechanism of solute transportation through NF membranes is not fully understood (Richards et al., 2011; Tang et al., 2011), and no efficient approach for accurately

4 simulating membrane performance has been presented (Verliefde et al., 2009), due to the 5 complex nature of the membrane surface and fouling species (Braghetta et al., 1997).

6 In this work, we studied the transport properties of oleuropein through NF membranes in 7 order to clarify and identify the important factors that control the transport mechanism 8 through an NF membrane. Aqueous oleuropein solution was selected as the model solution containing polyphenols. Performance flux and rejection of several commercial membranes were evaluated. This study provides a better understanding of the relationship between osmotic pressure and operating conditions. Also, we estimated values of flux decline after experimentally evaluating the flux decline caused by osmotic pressure and concentration polarization.

\section{MATERIALS AND METHODS}

\subsection{Reagents}

Oleuropein $\mathrm{C}_{25} \mathrm{H}_{32} \mathrm{O}_{13}$ (molecular weight $540.5 \mathrm{~g} \mathrm{~mol}^{-1}$, max. absorbance $\lambda \max =280 \mathrm{~nm}$ ), a polyphenol, was provided by Extrasynthese Co., Ltd. (Genay, France), with 85\% (w/w) oleuropein purity. The chemical structure of oleuropein is presented in Fig. 1. Milli-Q water was used for preparing different model solution concentrations $\left(0.3,0.9\right.$, or $\left.2.7 \mathrm{~kg} \mathrm{~m}^{-3}\right)$.

\subsection{Flat Sheet Membranes}

To evaluate the separation of oleuropein using an NF membrane, the performance of several commercial membranes was evaluated, considering their permeate flux $\left(J_{\mathrm{v}}\right)$ and 
1 observed rejection $\left(R_{\mathrm{obs}}\right)$. Eleven types of flat-sheet NF membranes, whose specific properties

2 are listed in Table 1, were tested.

\subsection{Membrane Experiment Procedure}

5

A flat-membrane test cell (Nitto Denko Co., Kusatsu, Japan) was operated in batch mode at room temperature $\left(25^{\circ} \mathrm{C}\right)$. The inner diameter of the cell was $7.0 \mathrm{~cm}$ with an effective membrane surface of $42.75 \times 10^{-4} \mathrm{~m}^{2}$. The experiment setup is schematically represented in Fig. 2. Experiments were conducted in a nitrogen atmosphere, and the operating pressure $(0$ to 40 bars) was controlled by adjusting the pressure regulator of the nitrogen cylinder. The membrane cell was placed on a magnetic stirrer and agitated ( 0 to $800 \mathrm{rpm}$ ) by a magnetic spin bar fitted inside the cell. The cell was loaded with a fixed quantity of feed solution. The permeated solution was collected through a port beneath the membrane support; the flux was recorded continuously using a personal computer interfaced with an electronic balance (model UX620H, Shimadzu, Japan).

To evaluate membrane performance, commercial NF membranes were tested with a model solution containing oleuropein $1 \mathrm{~kg} \mathrm{~m}^{-3}$, until a volume reduction factor (VRF) of 1.4 (see paragraph 2.4), (here, permeate volume represents $1 / 3$ of initial feed). A stirring rate of 500rpm was used (for a laminar hydrodynamic state with a fixed mass transfer and reduced turbulent shear effect), and the applied pressure was 20 bar. The membrane with the highest rejection was selected for further study with different applied pressures and fixed stirring rates. A low VRF value (1.05) was applied to determine the effect of applied pressure on $J_{\mathrm{V}}$ and transport parameters in order to eliminate the effect of batch concentration created in this stirred cell. The concentration of oleuropein in retentate $\left(C_{\text {ret }}\right)$ and permeate $\left(C_{\mathrm{p}}\right)$ was determined at each pressure level. 
$1 \quad 2.4$ Determination of Permeate Flux $\left(J_{\mathrm{v}}\right)$ and Observed Rejection $\left(R_{\mathrm{obs}}\right)$

2 The filtration efficiency in separating oleuropein was evaluated using the observed

3 rejection, which was calculated using the rejection formula in batch mode:

4

5

6

7

8

9

10

$$
R_{\mathrm{obs}}=\frac{\log (\mathrm{SCR})}{\log (\mathrm{VRF})}
$$

where SCR is the solute concentration ratio, defined as the ratio of the final retentate concentration $\left(\mathrm{kg} \mathrm{m}^{-3}\right)$ to the initial feed concentration $\left(\mathrm{kg} \mathrm{m}^{-3}\right)$ :

$$
\operatorname{SCR}=\frac{C_{\mathrm{ret}, f}}{C_{\mathrm{ret}, i}}
$$

and VRF is the volume reduction factor, defined as the ratio between the initial feed volume $\left(\mathrm{V}_{i}\right)$ and the final retentate volume $\left(\mathrm{V}_{f}\right)$ :

$$
\mathrm{VRF}=\frac{\mathrm{V}_{i}}{\mathrm{~V}_{f}}
$$

Also, filtration performance was evaluated through the permeate flux $\left(J_{\mathrm{v}}\right)$, which was calculated as

$$
J_{\mathrm{v}}=\frac{\mathrm{m}}{\Delta \mathrm{t} \cdot \rho \cdot \mathrm{A}}
$$

where $J_{\mathrm{v}}$ is the permeate flux $\left(\mathrm{m}^{3} \mathrm{~m}^{-2} \mathrm{~s}^{-1}\right), \rho$ is density of the permeate sample $\left(\mathrm{kg} \mathrm{m}^{-3}\right)$, measured weight, $\mathrm{m}(\mathrm{kg})$, collected within the time interval, $\Delta \mathrm{t}(\mathrm{s})$.

Density ( $\rho$ ) was measured using an electronic densitometer (DA-130N, KEM. Co., Ltd, Japan), and the effective membrane surface area (A) was kept constant at $42.75 \times 10^{-4} \mathrm{~m}^{2}$.

\subsection{Oleuropein Concentration and Osmotic Pressure}

The oleuropein concentration was measured using a V-530 UV/VIS spectrophotometer (Jasco, Japan) at $280 \mathrm{~nm}$, equipped with a matched pair of quartz cuvettes $(1 \mathrm{~cm}$ optical length). Plots of oleuropein concentration versus absorbance followed the Lambert-Beer law, within the concentration range used in the calibration curve, 0 to $0.3 \mathrm{~kg} \mathrm{~m}^{-3}$. Appropriate dilution with Milli-Q water was used to adjust the concentration in this range. 
1 Since oleuropein concentration in this study is relatively low (between 0.3 and $2.7 \mathrm{~kg} \mathrm{~m}^{-3}$ )

2 and the molecular weight of oleuropein $\left(\mathrm{M}_{\mathrm{olp}}=540.5 \mathrm{~g} \mathrm{~mol}^{-1}\right)$ is relatively large compared to

3 the molecular weight of water $\left(M_{w}=18 \mathrm{~g} \mathrm{~mol}^{-1}\right)$, the osmotic pressure could be calculated

$4 \quad$ using the van't Hoff equation:

$$
\Pi=\frac{R_{\mathrm{g}} \cdot \mathrm{T} \cdot \rho_{\mathrm{w}} \cdot C}{\mathrm{M}_{\mathrm{w}} \cdot C+\rho_{\mathrm{w}} \cdot \mathrm{M}_{\mathrm{olp}}}
$$

6 where $\Pi$ is osmotic pressure (bars), $C$ is oleuropein concentration $\left(\mathrm{kg} \mathrm{m}^{-3}\right), R_{\mathrm{g}}$ is the ideal gas 7 constant $\left(8.314 \mathrm{~J} \mathrm{~mol}^{-1} \mathrm{~K}^{-1}\right), \rho_{\mathrm{w}}$ is the water density at given temperature $\left(\mathrm{kg} \mathrm{m}^{-3}\right)$, and $\mathrm{T}$ is 8 the solution temperature (K) (Krishna \& van Baten, 2011; Liu et al., 2013; Van der Bruggen 9 et al., 2003).

If $C$ is very small and $\left(\mathrm{M}_{\mathrm{w}} \cdot C\right) \ll\left(\rho_{\mathrm{w}} \cdot \mathrm{M}_{\mathrm{olp}}\right)$, then

$$
\Pi=\frac{R_{\mathrm{g}} \cdot \mathrm{T} \cdot C}{\mathrm{M}_{\mathrm{olp}}}
$$

Equation (6) was applied in the following study to calculate oleuropein osmotic pressure.

\section{THEORETICAL ASPECT}

\subsection{Solution-Diffusion Model (Osmotic Pressure Model)}

For a two-component system consisting of water and a solute, the irreversible thermodynamic approach leads to two basic equations:

$$
\begin{gathered}
J_{\mathrm{v}}=L_{\mathrm{p}}^{\mathrm{w}} \cdot(\Delta \mathrm{P}-\sigma \Delta \Pi) \\
J_{\mathrm{s}}=\omega \cdot \Delta C_{s}+(1-\sigma) \cdot J_{\mathrm{v}} \cdot \bar{C}
\end{gathered}
$$

where $J_{\mathrm{v}}$ is the water flux $\left(\mathrm{m}^{3} \mathrm{~m}^{-2} \mathrm{~s}^{-1}\right), J_{\mathrm{s}}$ is the solute flux $\left(\mathrm{kg} \mathrm{m}^{-2} \mathrm{~s}^{-1}\right), \Delta \mathrm{P}$ is transmembrane pressure, $\Delta \Pi_{\mathrm{m}}$ is the osmotic difference between the two sides of the membrane (bar), $L_{\mathrm{p}}^{\mathrm{w}}$ is water permeability $\left(\mathrm{m}^{3} \mathrm{~m}^{-2} \mathrm{~s}^{-1}\right.$ bar $\left.^{-1}\right), \sigma$ is the reflection coefficient $(-), \omega$ is the solute

23 permeability $\left(\mathrm{m}^{3} \mathrm{~m}^{-2} \mathrm{~s}^{-1}\right), \bar{C}$ is the average solute concentration in the membrane $\left(\mathrm{kg} \mathrm{m}^{-3}\right)$, and 
$1 \Delta C_{\mathrm{s}}=C_{\mathrm{m}}-C_{\mathrm{p}}\left(\mathrm{kg} \mathrm{m}^{-3}\right)$, where $C_{\mathrm{m}}$ is the solute concentration at the membrane surface (in the

2 bulk side) and $C_{\mathrm{p}}$ is that in the permeate (Spiegler \& Kedem, 1966).

3 The pure water flux in a fresh membrane is expressed as:

4

5

6

7

$$
L_{\mathrm{p}}^{\mathrm{w}}=\frac{\Delta \mathrm{P}}{\left(\eta \cdot R_{\mathrm{m}}\right)}
$$

where $\eta$ is the viscosity of water at a given temperature (bar $\mathrm{s}$ ) and $R_{\mathrm{m}}$ is the intrinsic membrane resistance $\left(\mathrm{m}^{-1}\right)$.

The water permeability was evaluated for each tested commercial membrane at $25^{\circ} \mathrm{C}$, and the results are presented in Table $\mathbf{1 .}$

The characteristics of membrane transport were analyzed in terms of three coefficients or transport parameters: water permeability $\left(L^{\mathrm{w}}\right), \omega$, and $\sigma$, all of which can be determined experimentally. The water permeability coefficient can be obtained using Eq. (9) applied for experiments with pure water.

Considering that the osmotic pressure difference is zero, there is a linear relationship between the hydrodynamic pressure $(\Delta \mathrm{P})$ and the permeate flux $\left(J_{\mathrm{v}}\right)$. The water permeability coefficient can be obtained from the slope of the corresponding flux-pressure curve. Coefficients $\omega$ and $\sigma$ can be obtained by performing an osmotic and diffusion experiment. Rearranging Eq. (8), the following equation is obtained:

$$
\frac{J_{\mathrm{s}}}{\Delta C_{\mathrm{s}}}=\omega+(1-\sigma) \cdot J_{\mathrm{v}} \frac{\bar{C}}{\Delta C_{\mathrm{s}}}
$$

We plot $\left(J_{\mathrm{s}} / \Delta \mathrm{C}_{\mathrm{s}}\right)$ versus $\left(J_{\mathrm{v}} \cdot C / \Delta C_{\mathrm{s}}\right)$, obtaining $\omega$ from the intercept and $\sigma$ from the slope of the resulting straight curve. During osmotic pressure-controlled NF, the effect of concentration polarization is manifested solely as an increase in the osmotic pressure of the solution near the membrane surface.

For simulation of $J_{\mathrm{v}}$ using this model, osmotic pressure must be estimated as a function of solute concentration as a prerequisite. A common method is to use experiment correlations, which are usually expressed as virial expansions in concentration (Nabetani et al., 1990; 
1 Trettin \& Doshi, 1981; Van den Berg et al., 1989; Vilker et al., 1981; Wijmans et al., 1985).

2 Thus, a semi-empirical form of the van't Hoff equation (Flory, 1953) that relates osmotic

3 pressure to solute concentration is used.

4

$$
\Delta \Pi_{\mathrm{olp}}=\frac{R_{\mathrm{g}} \cdot \mathrm{T}}{\mathrm{M}_{\mathrm{olp}}} \cdot \Delta C_{\mathrm{s}}
$$

6

3.2 Concentration Polarization Model (Film Model)

During filtration, a steady-state condition is reached as a result of the balance between convective transport of solutes towards the membrane surface and diffusive back transport of retained solutes into the feed solution (Cheryan, 1986; Cornelissen et al., 2005; Strathmann, 1979). This is mathematically expressed by:

$$
J_{\mathrm{s}}=C_{\mathrm{p}} \cdot J_{\mathrm{v}}=C \cdot J_{\mathrm{v}}-D \frac{d C}{d x}
$$

where $D$ is the solute diffusion coefficient $\left(\mathrm{m}^{2} \mathrm{~s}^{-1}\right)$ (Kedem \& Katchalsky, 1958). Solving this equation over the laminar boundary layer with a thickness of the boundary layer $(\delta)$ gives (Fig. 3) (Kimura \& Sourirajan, 1967):

$$
\frac{C_{\mathrm{m}}-C_{\mathrm{p}}}{C_{\mathrm{ret}}-C_{\mathrm{p}}}=\exp \left(\frac{J_{\mathrm{v}}}{k}\right)
$$

The ratio of the diffusion coefficient $(D)$ to $\delta$ is known as the mass-transfer coefficient $(k)$. This coefficient depends strongly on the hydrodynamics of the system and can therefore be changed and optimized.

Solutes that are rejected by the membrane accumulate on the outer surface of the feed solution; therefore, the concentration at the interface $C_{\mathrm{m}}$ becomes larger than the feed concentration. Two types of rejection can be defined (Mitchell \& Deen, 1986; Nakao, 1986): observed rejection $\left(R_{\mathrm{obs}}\right)$

$$
R_{\mathrm{obs}}=1-C_{\mathrm{p}} / C_{\text {ret }}
$$

and intrinsic rejection $\left(R_{\text {int }}\right)$ 


$$
R_{\text {int }}=1-C_{\mathrm{p}} / C_{\mathrm{m}}
$$

$2 R_{\text {int }}$ should be used for determining membrane permeation properties. Equation (12) can be

3 transformed into $R_{\text {int }}$ and $R_{\text {obs }}$ as follows:

4

5

6

7

8 9 Kulcsár, 2010):

10

11

12

with

$$
\ln \left(\frac{1-R_{\mathrm{obs}}}{R_{\mathrm{obs}}}\right)=\ln \left(\frac{1-R_{\mathrm{int}}}{R_{\mathrm{int}}}\right)+\frac{J_{\mathrm{v}}}{k}
$$

The ratio of osmotic pressure at the membrane surface to osmotic pressure of the feed solution supply $\left(\Delta \Pi_{\mathrm{m}} / \Delta \Pi_{0}\right)$ is known as the concentration polarization modulus $(C P M)$ (Song \& Liu, 2012). This ratio increases (i.e., the concentration $C_{\mathrm{m}}$ at the membrane surface increases) with increasing $J_{\mathrm{v}}$, with increasing rejection, and with decreasing $k$ (Nagy \&

$$
C P M=\frac{\Delta \Pi_{\mathrm{m}}}{\Delta \Pi_{0}}=\frac{\left(C_{\mathrm{m}}-C_{\mathrm{p}}\right)}{\left(C_{\mathrm{ret}}-C_{\mathrm{p}}\right)}
$$

\subsection{Spiegler-Kedem Model for Simulating Intrinsic Rejection}

With constant fluxes and constant transport parameters $\left(L_{\mathrm{p}}^{\mathrm{w}}, \sigma\right.$, and $\left.\omega\right)$, integration of Eq.

(8) over the membrane thickness yields, in terms of the real solute rejection, leads to the following rejection expression $(R)$ (Spiegler \& Kedem, 1966):

$$
R_{\mathrm{int}}=\frac{\sigma(1-F)}{1-\sigma F}
$$

$$
F=\exp \left(-\frac{(1-\sigma)}{\omega} J_{\mathrm{v}}\right)
$$

From Eq. (18), retention increases with increasing permeate flux and reaches a limiting value $\sigma$ at an infinitely high permeate flux, as reported by Diawara et $a l$. (2003).

\subsection{Observed Rejection Simulation from the Concentration Polarization Model}

Equation (20) associates observed and intrinsic rejection, and involves the Peclet number $\left(P_{\mathrm{e}}\right)$ in the boundary layer (Causserand et al., 2004; Opong and Zydney, 1991): 


$$
R_{\text {int }}=\frac{R_{\mathrm{obs}} \exp \left(P_{\mathrm{e}}\right)}{1-R_{\mathrm{obs}}\left(1-\exp \left(P_{\mathrm{e}}\right)\right)}
$$

2 with

4 Here, $P_{\mathrm{e}}$ is a dimensionless number that expresses the ratio between convective flux and

$$
P_{\mathrm{e}}=\frac{J_{\mathrm{v}}}{k}
$$
diffusive flux in the concentration polarization layer.

If $P_{\mathrm{e}} \gg 1$, convection predominates in the boundary layer, concentration polarization is favored, and rejection decreases.

If $P_{\mathrm{e}} \ll<1$, diffusion significantly reduces the increase of concentration polarization. In this case, concentration polarization could be neglected.

\section{RESULTS AND DISCUSSION}

\subsection{Evaluation of NF Membrane Performance}

Figure 4 presents the results obtained for membrane performance. The observed rejection $\left(R_{\text {obs }}\right)$ of oleuropein was mostly within the range of 8 to $55 \%$, except for membrane Koch MPF44. The variation of $R_{\mathrm{obs}}$ for each NF membrane could be due to physical sieving caused by different membrane molecular weight cut-off (MWCO) (Van der Bruggen et al., 1999). As molecules become larger, sieving effects due to steric hindrance increase, and the molecule is rejected by the membrane more often than a smaller molecule (Bellona et al., 2004). Moreover, due to the low MW of oleuropein (540.51 $\mathrm{g} \mathrm{mol}^{-1}$ ), we could observe low oleuropein rejection (less than 30\%) by the NF membrane with MWCO exceeding oleuropein MW. The positive value of rejection could be explained by the fact that the rejection mechanism of organic solute is a combination of different factors related to the solute and membrane properties, especially membrane hydrophobicity and surface charge, which limits solute transportation (Macoun, 1999). 
1 In addition, MPF44 composite material consists of polyacrylonitrile (PAN) as support and

2 polydimethylsiloxane (PDMS) as the selective top layer that employs physicochemical

3 (electrostatic and steric) interactions between the membrane functional groups and solutes,

4 due to high interaction between the siloxane group of PDMS polymer (refer to Fig. 5) and the

5 oleuropein molecule. This results in sorption on the membrane surface of the oleuropein

6 molecule, suggesting the formation of a sorption monolayer on the membrane surface. The

7 negative charge of the membrane surface, created by the membrane methyl group

8 (Levenstain et al., 1996; Whu et al., 2000), increases the Donnan effect between oleuropein

9 and the membrane surface. Although the MWCOs of membranes DK and MPF34 are below

10 that of MPF44, rejection was lower for those membranes, due to the synergy of previous

11 factors (including steric hindrance as well as Donnan and dielectric effects) with membrane material properties (adsorptive interactions between membrane and solutes) (Bellona et al., 2004).

Regarding permeation performance, all tested membranes exhibited low flux (below $11 \times 10^{-6} \mathrm{~m}^{3} \mathrm{~m}^{-2} \mathrm{~s}^{-1}$ ), except for NTR7410, which exhibited high permeate flux up to $20.3 \times 10^{-6}$ $\mathrm{m}^{3} \mathrm{~m}^{-2} \mathrm{~s}^{-1}$, because the high MWCO of this membrane results in low resistance to water permeation.

The performances of all membranes tested were compared and MPF44 was selected for further investigation to clarify the factors affecting oleuropein transport in a high-pressure membrane system.

4.2 Transport of Oleuropein Through the MPF44 Membrane

4.2.1 Effect of applied pressure on permeate flux

Figure 6 illustrates the effect of applied pressure on permeate flux for oleuropein model solution with different oleuropein feed concentrations. The flux behavior was linear up to 20 
1 bar. Above this pressure, an increase of $\Delta \mathrm{P}$ leads to increasing $J_{\mathrm{v}}$ with different slopes related 2 to $C_{0}$.

$3 \quad$ Figure 6 enables the quantification of $x$-intercept (at $J_{v}=0$ ) for each feed concentration,

4 which is equivalent to the osmotic pressure $\sigma \Delta \Pi_{0}$ that indicates the difference in osmotic

5 pressure between the retentate and permeate solution for zero permeate flux transfer (refer to 6 osmotic model, Eq. (7)). For high solute rejection, $\Delta \Pi_{0}$ could be estimated using the van't

7 Hoff equation (Eq. (11)). The calculated osmotic pressure is in good agreement with the 8 experiment value (with $10 \%$ experimental error) of those obtained from the $x$-intercept 9 (Table 2).

To evaluate the reversibility of the concentration polarization mechanism, we adopted membrane washing with water to remove all compounds adsorbed at the membrane surface. The water permeate flux obtained after washing the membrane surface is a regenerated water flux (Fig. 6).

This observation is the consequence of concentration polarization, which causes the reduction of $J_{\mathrm{v}}$ by the limiting osmotic pressure causing back diffusive flux against $J_{\mathrm{v}}$ (Fig. 3). For applied pressure less than the limiting osmotic pressure, the permeate flux was negative, due to the positive limiting osmotic pressure $\left(\Delta \Pi_{0}\right)$.

Above this pressure, an increase of applied pressure leads to flux increases with different slopes related to $C_{0}$. In fact, the limiting osmotic pressure becomes more important, due to high solute accumulation at the membrane surface with high $C_{0}$.

As a consequence of increased $\Delta \Pi$ due to concentration polarization, it was necessary to increase pressure to maintain a constant flux, which means a higher operating cost for the filtration process. 
1 From the concentration polarization model (for complete rejection of solute) at the

2 membrane surface, we could deduce the mass-transfer coefficient from the inverse of the

3 slope of the curve $\ln \left(\frac{C_{\mathrm{m}}-C_{\mathrm{p}}}{C_{\mathrm{ret}}-C_{\mathrm{p}}}\right)=\frac{J_{\mathrm{v}}}{k}$ (Fig. 7). The experiment value of $k$ was $8.80 \times 10^{-6} \mathrm{~m} \mathrm{~s}^{-1}$.

4 This is constant throughout the filtration experiment in this study, because the hydrodynamic

5 condition (i.e., stirring rate for the stirred batch cell) was kept constant during all the

6 experiments. In addition, the diffusion coefficient $(D)$ change with oleuropein concentration

7 was neglected.

8

$9 \quad$ 4.2.3 Transport parameters of oleuropein through the MPF44 membrane

10 Non-equilibrium thermodynamics was applied to the NF membrane, as well as to dilute

11 solutions consisting of a solvent and a solute. The characteristics of the NF membrane in such

systems may be described in terms of three transport parameters $L_{\mathrm{p}}{ }^{\mathrm{w}}, \omega$, and $\sigma$, which could be obtained by performing osmotic and diffusion experiments.

14 As indicated in Eq. (10), by plotting $\left(\frac{J_{\mathrm{S}}}{\Delta C_{\mathrm{S}}}\right)$ versus $\left(J_{\mathrm{v}} \frac{\bar{C}}{\Delta C_{\mathrm{S}}}\right)$, $\omega$ is obtained from the intercept of $15 y$-axis, and $\sigma$ from the slope of the resulting nearly straight curve $\left(\mathrm{R}^{2}=0.975\right)($ Fig. 8).

16 The value obtained for $\omega$ was $1.14 \times 10^{-6} \mathrm{~m}^{3} \mathrm{~m}^{-2} \mathrm{~s}^{-1}$, and that obtained for $\sigma$ was 0.932 . The 17 obtained $\omega$ is lower than $k$ because of the high value of $\sigma$ related to the major contribution of 18 the molecular size of oleuropein compared to membrane pore size.

\subsubsection{Osmotic pressure at membrane surface}

Where $J_{\mathrm{v}}$ is influenced by only the osmotic pressure of solute, we can calculate the difference in osmotic pressure $\Delta \Pi_{\mathrm{m}}$ for each applied pressure (Spiegler \& Kedem, 1966). Equation (7) could be rearranged as

$$
\sigma \Delta \Pi_{\mathrm{m}}=\Delta \mathrm{P}-\frac{J_{\mathrm{v}}}{L_{\mathrm{p}}^{\mathrm{W}}}
$$


1 where $\Delta \Pi_{\mathrm{m}}$ is the difference between osmotic pressure of the bulk solution at the membrane

2 surface $\left(\Pi_{\mathrm{m}}\right)$ and the permeate solution $\left(\Pi_{\mathrm{P}}\right)$.

3

$$
\Delta \Pi_{\mathrm{m}}=\Pi_{\mathrm{m}}-\Pi_{\mathrm{p}}
$$

The increase of $\Pi_{\mathrm{m}}$ in relation to the applied pressure was due to the accumulation of oleuropein at the membrane surface caused by the concentration polarization phenomenon, which increases with permeate flux coupling the solvent/solute transport through the membrane surface barrier.

The osmotic pressure $(\Pi)$ of the model solutions correlated with the obtained calibration curve with the relationship of osmotic pressure and oleuropein concentration $(C)$ was:

$$
\Pi=46 \times 10^{-4} \times C
$$

This allowed estimating the concentration of oleuropein in the surface of the membrane $\left(C_{\mathrm{m}}\right)$ (Table 3).

As indicated in Table 3, the concentration polarization phenomenon increases the gradient of osmotic pressure $\Delta \Pi_{\mathrm{m}}$ on either side of the membrane and reduces the effective applied pressure (Balannec et al., 1999; Nicolas et al., 2000).

$C P M$ increased from 2.0 to 17.7 for the oleuropein solution initially containing $0.3 \mathrm{~kg} \mathrm{~m}^{-3}$ at applied pressure 5 to 40 bar, respectively. Here, $\sigma \Delta \Pi_{\mathrm{m}}$ had the highest initial value for high oleuropein concentration $\left(2.7 \mathrm{~kg} \mathrm{~m}^{-3}\right)$, due to the high concentration of bulk solution contributing to a high deposit of oleuropein molecules at the membrane surface and resulting in high osmotic pressure on the bulk side.

\subsubsection{Flux decline due to the osmotic effects $\left(\Delta J_{\text {osm }}\right)$}

Figure 6 plots the increase of $J_{\mathrm{v}}$ as a function of $\Delta \mathrm{P}$ for a given oleuropein concentration. Intersections of $J_{\mathrm{v}}$ curves with the $\Delta \mathrm{P}$-axis are relatively small, since osmotic pressure in the bulk solution is relatively small (Table 2). 
1 For a given $\Delta \mathrm{P}, J_{\mathrm{v}}$ decreases as a function of $C_{0}$. A higher $C_{0}$ yields a higher $C_{\mathrm{m}}$ due to the

2 concentration polarization phenomenon. As a result, solutions with a higher $C_{\mathrm{m}}$ exhibited

3 higher osmotic pressure at the membrane surface $\Pi_{m}$ (Table 3). The effect of the resulting $\Pi_{m}$

4 on $J_{\mathrm{v}}$ decreases is represented as the flux decline concept in Fig. 9.

$5 \quad$ Figure 9 depicts the flux decline concept and quantifies the effect of $\Pi_{m}$ on the decrease

6 of $J_{\mathrm{v}}$. Using the osmotic pressure model, we obtain (Bhattacharjee et al., 1996; El Khabbaze, 7 2008):

$$
J_{\mathrm{v}}=\frac{\Delta \mathrm{P}-\sigma \Delta \Pi_{\mathrm{m}}}{\mu R_{\mathrm{m}}}=\frac{\Delta \mathrm{P}}{\mu R_{\mathrm{m}}}-\frac{\sigma \Pi_{\mathrm{m}}}{\mu R_{\mathrm{m}}}=J_{\mathrm{w}}-\Delta J_{\mathrm{osm}}
$$

9 We could also define $J_{\mathrm{w}}$ (water flux) and $\Delta J_{\text {osm }}$ (flux decline due to osmotic effect):

$$
\Delta J_{\mathrm{osm}}=\frac{\sigma \Delta \Pi_{\mathrm{m}}}{\eta \cdot \mathrm{R}_{\mathrm{m}}}
$$

$J_{\mathrm{v}}$ was affected mainly by the osmotic effect, regardless of applied pressure (5 to 40 bar), and the fouling effect was neglected due to the linearity of $J_{\mathrm{v}}$ with respect to the applied pressure. The increase of osmotic effect was proportional to the increase of applied pressure, which represents the driving force for transport of both water and solute across the membrane, leading to the increase of oleuropein at the membrane barrier. This phenomenon leads to a highly concentrated layer of oleuropein near the membrane surface, and this layer resists the mass transfer of permeate.

\subsection{Rejection of oleuropein by the MPF44 membrane}

To examine the accuracy of the determined transport parameters, intrinsic rejection $R_{\text {int }}$ was simulated using the Spiegler-Kedem model (Eq. (18)) with these values, and $J_{\mathrm{v}}$ versus $P_{\mathrm{e}}$ was plotted as a continuous curve (Fig. 10). $R_{\text {int }}$ increases steadily until it reaches a threshold 
1 value $R_{\infty}$ for which the intrinsic rejection was kept constant. In Eq. (19), F $\rightarrow 0$ at high flux;

2 hence, the reflection coefficient $\sigma$ is the limiting value of $R_{\text {int }}$.

$3 \quad J_{\mathrm{v}}, P_{\mathrm{e}} \rightarrow \infty ; R_{\text {int }} \rightarrow \sigma$

$4 \quad R_{\text {obs }}$ can be simulated using the concentration polarization model (Eq. (20)). The dashed

5 curve in Fig. 10 denotes the relationship of simulated $R_{\text {obs }}$ versus $J_{\mathrm{v}}$ and $P_{\mathrm{e}}$. The experiment

6 data of $R_{\text {obs }}$ is also plotted for each oleuropein concentration $\left(C_{0}\right)$.

$7 \quad$ At the low flux region, the simulated $R_{\text {obs }}$ agreed well with the simulated $R_{\text {int }}$, until certain

8 values of $J_{\mathrm{v}}\left(\approx 0.3 \times 10^{-6} \mathrm{~m}^{3} \mathrm{~m}^{-2} \mathrm{~s}^{-1}\right)$ and $P_{\mathrm{e}}(\approx 0.1)$

9 The diffusive back transport of retained solute into feed solution remains constant when the applied pressure increases (Paugam et al., 2004) (see paragraph 2.5.4).

The Spiegler-Kedem theory asserts that rejection increases with increased $J_{\mathrm{v}}$ and remains constant when the driven force $(\Delta \mathrm{P})$ becomes dominant (Dobrak et al., 2011). Equations (13) and (14) were used to simulate $R_{\text {int }}$ with respect to $\Delta \mathrm{P}$. The concentration of oleuropein $C_{\text {ret }}$ was similar to that at the membrane surface $\left(C_{\text {ret }} \approx C_{\mathrm{m}}\right)$ (Table 3). Thus, simulated $R_{\text {int }}$ and $R_{\mathrm{obs}}$ are superposed and exhibit the same behavior. Also, the experiment data of $R_{\mathrm{obs}}$ are consistent with this behavior.

In the region of high flux, the simulated $R_{\text {obs }}$ deviated from the Spiegler-Kedem model at all tested concentrations. This occurs at a critical pressure where the diffusive back transport is surpassed by pressure forces (Cancino-Madariaga et al., 2011; Paugam et al., 2004; Pontalier et al., 1999; Pontalier et al., 1997).

Once this pressure is exceeded, the solute is pushed through the membrane, and rejection is decreased. Also, Eqs. (13) and (14) were used to interpret the decrease of $R_{\text {obs. }}$ The increases in $C_{\mathrm{m}}$ at the membrane surface (regarding the concentration polarization phenomenon) lead to a lower $C_{\text {ret }}$ compared to $C_{\mathrm{m}}$ (Table 3), which gradually worsens with increasing $J_{\mathrm{v}}$ (and the 
1 applied pressure). Table 4 indicates errors between simulated and experiment values of $R_{\mathrm{obs}}$,

2 using Eq. (28).

$$
\text { Error }=\frac{\left(R_{\text {obs }}\right)_{\text {exp. }}-\left(R_{\text {obs }}\right)_{\text {pred. }}}{\left(R_{\text {obs }}\right)_{\text {exp. }}} \times 100
$$

4 The absolute values varied from 0.11 to $22 \%$. Most of the calculated errors in Table 4 are

5 below $5 \%$. The errors were obtained at the highest $J_{\mathrm{v}}$ for all the feed concentrations. The

6 absence of electrostatic interactions in the Spiegler-Kedem model and the film model and the

7 expected content of charge at the oleuropein molecule could explain why the simulated $R_{\text {obs }}$

8 deviates from the experiment values.

9

\section{CONCLUSIONS}

Based on the results obtained in this study, we conclude the following.

- The osmotic pressure model and the concentration polarization model are good analytic models for obtaining membrane transport parameters, simulating the NF process performance, and optimizing the process.

- Permeate flux was governed mainly by the osmotic pressure of oleuropein. Flux declines following the accumulation of oleuropein at the membrane surface, forming a concentration polarization layer with lower hydraulic resistance than membrane resistance.

- Modeling oleuropein intrinsic rejection using the Spiegler-Kedem model fitted well with the experiment results.

- Osmotic pressures at the membrane surface are calculated considering the high observed rejection of oleuropein. We can directly access the oleuropein concentration at the membrane surface from the ratio of oleuropein osmotic pressure at the membrane surface to that of retentate, which is actually the concentration polarization modulus in this particular case. The mathematical model clearly indicates that oleuropein concentration at the membrane surface was higher for higher applied pressure. To compare the effects of osmotic pressure on 
1 permeate flux decline, data regarding flux decreases were presented as flux decline $\Delta J_{\text {osm. }}$.

2 The obtained mathematical model enables the association of permeate flux with flux decline

3 due to osmotic pressure opposite the applied pressure.

4 It is likely that the oleuropein molecule was responsible for the osmotic pressure and, as a

5 consequence, limited the permeate flux. Application of the NF membrane should reduce the

6 osmotic pressure and decrease the effective applied pressure and filtration performance, so

7 that the energy requirements can be reduced. The obtained results could be used as simple

8 calculation of the separation efficiency of oleuropein and other polyphenols.

9

10 List of Symbols

11 Variables

12 A : effective membrane surface area, $\left[\mathrm{m}^{2}\right]$

$13 \quad C \quad: \quad$ oleuropein concentration, $\left[\mathrm{kg} \mathrm{m}^{-3}\right]$

$14 \quad C_{\mathrm{m}}:$ oleuropein concentration at membrane surface, $\left[\mathrm{kg} \mathrm{m}^{-3}\right]$

$15 C_{\mathrm{p}}:$ oleuropein concentration in the permeate side, $\left[\mathrm{kg} \mathrm{m}^{-3}\right]$

$16 C_{\text {ret }}:$ oleuropein concentration in the retentate side, $\left[\mathrm{kg} \mathrm{m}^{-3}\right]$

$17 \quad \bar{C} \quad: \quad$ average oleuropein concentration in the membrane, $\left[\mathrm{kg} \mathrm{m}^{-3}\right]$

$18 C P M:$ concentration polarization modulus, $[-]$

$19 J_{\mathrm{s}} \quad$ : $\quad$ solute flux, $\left[\mathrm{kg} \mathrm{m}^{-2} \mathrm{~s}^{-1}\right]$

$20 J_{\mathrm{v}} \quad: \quad$ permeate flux, $\left[\mathrm{m}^{3} \mathrm{~m}^{-2} \mathrm{~s}^{-1}\right]$

$21 \quad k \quad: \quad$ mass transfer coefficient of solute in the boundary layer, $\left[\mathrm{m} \mathrm{s}^{-1}\right]$

$22 L_{\mathrm{p}}{ }^{\mathrm{w}} \quad$ : water permeability, $\left[\mathrm{m}^{3} \mathrm{~m}^{-2} \mathrm{~h}^{-1}\right.$ bar $\left.^{-1}\right]$

$23 \mathrm{M}_{\mathrm{olp}}:$ molecular weight of oleuropein, $\left[\mathrm{g} \mathrm{mole}^{-1}\right.$ ]

$24 \quad P_{\mathrm{e}}:$ peclet number, [-]

$25 \quad R \quad: \quad$ oleuropein rejection, [-] 
$1 \quad R_{\mathrm{g}} \quad$ : $\quad$ universal gas constant, $\left[\mathrm{J} \mathrm{mole}^{-1} \mathrm{~K}^{-1}\right.$ ]

$2 \quad R_{\infty}:$ maximum rejection, [-]

$3 \quad R_{\text {obs }}:$ observed rejection, [-]

$4 \quad R_{\text {int }} \quad: \quad$ intrinsic rejection, [-]

5 SCR : solute concentration ratio, [-]

$6 \quad t \quad:$ time, $[\mathrm{s}]$

$7 \mathrm{~T}:$ : temperature, $\left[{ }^{\circ} \mathrm{C}\right]$

8 VRF : volume reduction factor, [-]

9

10 Subscripts

$11 \mathrm{~m}$ : at membrane surface, [-]

12 int : intrinsic, [-]

13 obs : observed, [-]

14 i : initial, [-]

$15 \mathrm{f}$ : final, [-]

$16 \mathrm{p}$ : permeate, [-]

17 ret : retentate, [-]

18 olp : oleuropein, [-]

19 W : water, [-]

$20 \mathrm{~V}$ : volumetric, [-]

21 s : solute, [-]

22

23 Greek symbols

$24 \Pi \quad$ : $\quad$ osmotic pressure, [bar]

$25 \quad \sigma \quad: \quad$ reflection coefficient, [-] 
$1 \omega:$ : solute permeability, $\left[\mathrm{m}^{3} \mathrm{~m}^{-2} \mathrm{~s}^{-1}\right]$

$2 \Delta C_{\mathrm{s}}:$ concentration difference between membrane surface and permeate side, $\left[\mathrm{kg} \mathrm{m}^{-3}\right]$

$3 \Delta \mathrm{P}:$ membrane pressure gradient, [bar]

$4 \quad \rho_{\mathrm{w}} \quad:$ water density at given temperature, $\left[\mathrm{kg} \mathrm{m}^{-3}\right]$

5

6 Acknowledgements

7 This research was funded by the Science and Technology Research Partnership for

8 Sustainable Development (SATREPS) project of JICA/JST, Japan.

9

10

\section{References}

Agalias, A., Magiatis, P., Skaltsounis, A.L., Mikros, E., Tsarbopoulos, A., Gikas, E., Spanos, I., Manios, T., 2007. A new process for the management of olive oil mill waste water and recovery of natural antioxidants. J. Agric. Food Chem. 55, 2671-2676.

Al-Azzawie, H.F., and Alhamdani, M.S.S., 2006. Hypoglycemic and antioxidant effect of oleuropein in alloxan-diabetic rabbits. Life Sci. 78, 1371-1377.

Balannec, B., Nicolas, S., Bariou, B., 1999. Experimental study and modelization of reverse osmosis with salt solutes in an unstirred batch cell. Desalination 122, 43-51.

Bellona, C., Drewes, J.E., Xu, P., Amy, G., 2004. Factors affecting the rejection of organic solutes during NF/RO treatment-a literature review. Water Res. 38, 2795-2809.

Bhattacharjee, S., Sharma, A., Bhattacharya, P., 1996. A unified model for flux prediction during batch cell ultrafiltration. J. Membrane Sci. 111, 243-258.

Braghetta, A., DiGiano, F.A., Ball, W.P., 1997. Nanofiltration of natural organic matter: pH and ionic strength effects. J. Environ. Eng. 123, 628-641. 
1 Cancino-Madariaga, B., Hurtado, C.F., Ruby, R., 2011. Effect of pressure and pH in

2 ammonium retention for nanofiltration and reverse osmosis membranes to be used in

3 recirculation aquaculture systems (RAS). Aquacult. Eng. 45, 103-108.

4 Causserand, C., Rouaix, S., Akbari, A., Aimar, P., 2004. Improvement of a method for the 5 characterization of ultrafiltration membranes by measurements of tracers retention. J. 6 Membrane Sci. 238, 177-190.

7 Cheryan, M., 1986. Ultrafiltration handbook. Technomic Publishing Inc., Pennsylvania, pp. 73-123.

9 Cornelissen, E.R., Verdouw, J., Gijsbertsen-Abrahamse, A.J., Hofman, J.A., 2005. A nanofiltration retention model for trace contaminants in drinking water sources. Desalination 178, 179-192.

Diawara, C.K., Lô, S.M., Rumeau, M., Pontie, M., Sarr, O., 2003. A phenomenological mass transfer approach in nanofiltration of halide ions for a selective defluorination of brackish drinking water. J. Membrane Sci. 219, 103-112.

Dobrak-Van Berlo, A., Vankelecom, I.F., Van der Bruggen, B., 2011. Parameters determining transport mechanisms through unfilled and silicalite filled PDMS-based membranes and dense PI membranes in solvent resistant nanofiltration: Comparison with pervaporation. J. Membrane Sci. 374, 138-149.

El Khabbaze, H., 2008. Traitement des solutions modèles du lait par des membranes de nanofiltration et d'osmose inverse. Rennes1-Bu Sciences Philo, France, pp. 121-230.

Flory, J., P., 1953. Principles of polymer chemistry. Cornell University Press, New York.

Garcia-Castello, E., Cassano, A., Criscuoli, A., Conidi, C., Drioli, E., 2010. Recovery and concentration of polyphenols from olive mill wastewaters by integrated membrane system. Water Res. 44, 3883-3892. 
1 Gutierrez-Rosales, F., Romero, M.P., Casanovas, M., Motilva, M.A.J., Mínguez-Mosquera, M.I., 2012. $\beta$-Glucosidase involvement in the formation and transformation of oleuropein during the growth and development of olive fruits (Olea europaea L. cv. Arbequina) grown under different farming practices. J. Agric. Food Chem. 60, 4348-4358.

Kedem, O.T., and Katchalsky, A., 1958. Thermodynamic analysis of the permeability of biological membranes to non-electrolytes. Bioch. Bioph. Acta 27, 229-246.

Kimura, S., and Sourirajan, S., 1967. Analysis of data in reverse osmosis with porous cellulose acetate membranes used. AICHE J. 13, 497-503.

Krishna, R., and van Baten, J.M., 2011. Influence of adsorption on the diffusion selectivity for mixture permeation across mesoporous membranes. J. Membrane Sci. 369, 545-549.

Levenstein, R., Hasson, D., Semiat, R., 1996. Utilization of the Donnan effect for improving electrolyte separation with nanofiltration membranes, J. Membrane Sci. 116, 77.

Le Tutour, B., and Guedon, D., 1992. Antioxidative activities of Olea europaea leaves and related phenolic compounds. Phytochemistry. 31, 1173-1178.

Liu, L., Sanders, E.S., Johnson, J.R., Karvan, O., Kulkarni, S., Hasse, D.J., Koros, W.J., 2013. Influence of membrane skin morphology on $\mathrm{CO}_{2} \mathrm{~N}_{2}$ separation at sub-ambient temperatures. J. Membrane Sci. 446, 433-439.

Macoun, R.G., 1998. The mechanisms of ionic rejection in nanofiltration, Chemical Engineering, Ph.D. thesis, University of New South Wales, Sydney, Australia, pp. 121125.

Malik, N.S.A., and Bradford, J.M., 2008. Recovery and stability of oleuropein and other phenolic compounds during extraction and processing of olive (Olea europaea L.) leaves. J. Food Agric. Environ. 6, 8-13.

Mitchell, B. D., and W. M. Deen, 1986. Effect of Concentration on the Rejection Coefficients of Rigid Macromolecules in Track-Etch Membranes. J. Colloid Interf. Sci., 113, 1132. 
1 Nabetani, H., Nakajima, M., Watanabe, A., Nakao, S.I., Kimura, S., 1990. Effects of osmotic

2 pressure and adsorption on ultrafiltration of ovalbumin. AICHE J. 36, 907-915.

3 Nagy, E., and Kulcsár, E., 2010. The effect of the concentration polarization and the 4 membrane layer mass transport on membrane separation. Desal. Water Treat. 14, 220-226.

5 Nakao, S., 1986. Membrane Transport Phenomena and Ultrafiltration, Encyclopedia of Fluid $6 \quad$ Mechanics, Gulf Pub., Houston, pp. 987.

7 Nicolas, S., Balannec, B., Beline, F., Bariou, B., 2000. Ultrafiltration and reverse osmosis of small non-charged molecules: a comparison study of rejection in a stirred and an unstirred batch cell. J. Membrane Sci. 164, 141-155.

Opong, W.S., and Zydney, A.L., 1991. Diffusive and convective protein transport through asymmetric membranes. AICHE J. 37, 1497-1510.

Paugam, L., Taha, S., Dorange, G., Jaouen, P., Quéméneur, F., 2004. Mechanism of nitrate ions transfer in nanofiltration depending on pressure, $\mathrm{pH}$, concentration and medium composition. J. Membrane Sci. 231, 37-46.

Pontalier, P.-Y., Ismail, A., Ghoul, M., 1997. Mechanisms for the selective rejection of solutes in nanofiltration membranes. Sep. Purif. Technol. 12, 175-181.

Pontalier, P.-Y., Ismail, A., Ghoul, M., 1999. Specific model for nanofiltration. J. Food Eng. $40,145-151$.

Qi, B., Luo, J., Chen, X., Hang, X., Wan, Y., 2011. Separation of furfural from monosaccharides by nanofiltration. Biores. Technol. 102, 7111-7118.

Ranalli, A., Contento, S., Lucera, L., Di Febo, M., Marchegiani, D., Di Fonzo, V., 2006. Factors affecting the contents of iridoid oleuropein in olive leaves (Olea europaea L.). J. Agric. Food Chem. 54, 434-440. 
1 Richards, L.A., Richards, B.S., Schäfer, A.I., 2011. Renewable energy powered membrane

2 technology: Salt and inorganic contaminant removal by nanofiltration/reverse osmosis. J. Membrane Sci. 369, 188-195.

Saliha, B., Patrick, F., Anthony, S., 2009. Investigating nanofiltration of multi-ionic solutions using the steric, electric and dielectric exclusion model. Chem. Eng. Sci. 64, 3789-3798.

Servili, M., Baldioli, M., Selvaggini, R., Macchioni, A., Montedoro, G.F., 1999. Phenolic compounds of olive fruit: one- and two-dimensional nuclear magnetic resonance characterization of nüzhenide and its distribution in the constitutive parts of fruit. J. Agric. Food Chem. 47, 12-18.

Sheu, J.R., Hsiao, G., Chou, P.H., Shen, M.Y., Chou, D.S., 2004. Mechanisms involved in the antiplatelet activity of rutin, a glycoside of the flavonol quercetin, in human platelets. J. Agric. Food Chem. 52, 4414-4418.

Song, L., and Liu, C., 2012. A total salt balance model for concentration polarization in crossflow reverse osmosis channels with shear flow. J. Membrane Sci. 401, 313-322.

Spiegler, K., and Kedem, O., 1966. Thermodynamics of hyperfiltration (reverse osmosis): criteria for efficient membranes. Desalination 1, 311-326.

Stafie, N., Stamatialis, D., Wessling, M., 2005. Effect of PDMS cross-linking degree on the permeation performance of PAN/PDMS composite nanofiltration membranes. Sep. Purif. Technol. 45, 220-231.

Strathmann, H., 1979. Trennung von molekularen Mischungen mit Hilfe synthetischer Membranen. Darmstadt: Steinkopf., Germany, pp. 215-220.

Takaç, S., and Karakaya, A., 2009. Recovery of phenolic antioxidants from olive mill wastewater. Recent Pat. Chem. Eng. 2, 230-237.

Tang, C.Y., Chong, T., Fane, A.G., 2011. Colloidal interactions and fouling of NF and RO membranes: A review. Adv. Colloid Interf. Sci. 164, 126-143. 
1 Trettin, D.R., and Doshi, M.R., 1981. Pressure independent ultrafiltration-is it gel limited or 2 osmotic pressure limited?. Synth. Membranes 2, 373-409.

3 Van den Berg, G., Racz, I., Smolders, C., 1989. Mass transfer coefficients in cross-flow $4 \quad$ ultrafiltration. J. Membrane Sci. 47, 25-51.

5 Van der Bruggen, B., Schaep, J., Wilms, D., Vandecasteele, C., 1999. Influence of molecular 6 size, polarity and charge on the retention of organic molecules by nanofiltration. J. $7 \quad$ Membrane Sci. 156, 29-41.

8 Van der Bruggen, B., Vandecasteele, C., Van Gestel, T., Doyen, W., Leysen, R., 2003. A 9 review of pressure-driven membrane processes in wastewater treatment and drinking water 10 production. Environ. Progress 22, 46-56.

Verliefde, A.R., Cornelissen, E.R., Heijman, S.G., Hoek, E.M., Amy, G.L., Bruggen, B.V.d., van Dijk, J.C., 2009. Influence of solute-membrane affinity on rejection of uncharged organic solutes by nanofiltration membranes. Environ. Sci. Technol. 43, 2400-2406.

Vilker, V.L., Colton, C.K., Smith, K.A., 1981. The osmotic pressure of concentrated protein solutions: effect of concentration and $\mathrm{pH}$ in saline solutions of bovine serum albumin. $\mathrm{J}$. Colloid Interf. Sci. 79, 548-566.

Whu, J.A., Baltzis, B.C., Sirkar, K.K., 2000. Nanofiltration studies of larger organic microsolutes in methanol solutions. J. Membrane Sci. 170, 159-172.

Wijmans, J., Nakao, S., Van Den Berg, J., Troelstra, F., Smolders, C., 1985. Hydrodynamic resistance of concentration polarization boundary layers in ultrafiltration. J. Membrane Sci. 22, 117-135.

Yaroshchuk, A.E., 2008. Negative rejection of ions in pressure-driven membrane processes. Adv. Colloid Interf. Sci. 139, 150-173. 
Table 1 - Major characteristics of NF membranes used in this study.

\begin{tabular}{|c|c|c|c|c|c|}
\hline $\begin{array}{c}\text { Membrane } \\
\text { type }\end{array}$ & Manufacturer & $\begin{array}{c}\text { Skin-layer } \\
\text { Material }\end{array}$ & MWCO* & $\begin{array}{c}\text { Rejection } \\
\text { at test } \\
\text { conditions* }\end{array}$ & $\begin{array}{c}\text { Average water } \\
\text { permeability } \\
\left(L_{\mathrm{p}}^{\mathrm{w}}\right) \times 10^{-6}\left(\mathrm{~m}^{3} \mathrm{~m}^{-2}\right. \\
\left.\mathrm{s}^{-1} \mathrm{bar}^{-1}\right)\end{array}$ \\
\hline DK & $\begin{array}{c}\text { Osmonics Desal, } \\
\text { USA }\end{array}$ & $\mathrm{PA} / \mathrm{PS}^{\mathrm{a}}$ & $150^{\mathrm{b}}$ & $\begin{array}{c}98 \% \\
(2 \% \mathrm{MgSO} 4)\end{array}$ & 1.53 \\
\hline DL & $\begin{array}{c}\text { Osmonics Desal, } \\
\text { USA }\end{array}$ & $\mathrm{PA} / \mathrm{PS}$ & $300^{\mathrm{b}}$ & $\begin{array}{c}96 \% \\
(2 \% \mathrm{MgSO} 4)\end{array}$ & 2.11 \\
\hline G10 & $\begin{array}{c}\text { Osmonics Desal, } \\
\text { USA }\end{array}$ & $\mathrm{PEG}^{\mathrm{c}}$ & $2500^{\mathrm{d}}$ & $\begin{array}{c}10 \% \\
(10 \% \mathrm{NaCl})\end{array}$ & 0.88 \\
\hline G5 & $\begin{array}{c}\text { Osmonics Desal, } \\
\text { USA }\end{array}$ & PEG & $1000^{\mathrm{e}}$ & $\begin{array}{c}99.8 \% \\
(2 \% \mathrm{PEG})\end{array}$ & 0.33 \\
\hline MPF34 & $\mathrm{KOCH}$, USA & $\mathrm{SB} / \mathrm{PS}^{\mathrm{f}}$ & $200^{\mathrm{d}}$ & $\begin{array}{c}89 \% \\
(5 \% \mathrm{NaCl})\end{array}$ & 0.36 \\
\hline MPF36 & $\mathrm{KOCH}$, USA & SB/PS & $1000^{\mathrm{d}}$ & $\begin{array}{c}60 \% \\
(5 \% \mathrm{NaCl})\end{array}$ & 8.65 \\
\hline MPF44 & KOCH, USA & $\mathrm{SB} / \mathrm{PS}$ & $250^{\mathrm{g}}$ & $\begin{array}{c}98 \% \\
\text { (5\% sucrose) }\end{array}$ & 0.36 \\
\hline NTR7250 & $\begin{array}{l}\text { Nitto Denko Co., } \\
\text { JP }\end{array}$ & $\mathrm{PVA}^{\mathrm{h}}$ & $300-400^{\mathrm{d}}$ & $\begin{array}{c}60 \% \\
(0.2 \% \mathrm{NaCl})\end{array}$ & 1.83 \\
\hline NTR7410 & $\begin{array}{l}\text { Nitto Denko Co., } \\
\text { JP }\end{array}$ & SPES $^{\mathrm{i}}$ & $17500^{\mathrm{d}}$ & $\begin{array}{c}10 \% \\
(0.2 \% \mathrm{NaCl})\end{array}$ & 13.88 \\
\hline NTR7430 & $\begin{array}{l}\text { Nitto Denko Co., } \\
\text { JP }\end{array}$ & SPES & $2000^{\mathrm{b}}$ & $\begin{array}{c}30 \% \\
(5 \% \mathrm{NaCl})\end{array}$ & 6.28 \\
\hline NTR7450 & $\begin{array}{c}\text { Nitto Denko Co., } \\
\text { JP }\end{array}$ & SPES & $700-800^{d}$ & $\begin{array}{c}60 \% \\
(5 \% \mathrm{NaCl})\end{array}$ & 2.55 \\
\hline
\end{tabular}

* As provided by the manufacturer,

${ }^{a}$ PA/PS: Aromatic polyamide on polysulfone support,

c PEG: Polyethylene glycine,

h PVA: Polyvinyl alcohol,

i SPES: Sulfonated polyether sulfone,

f SB/PS: Silicone on polysulfone support,

b Based on rejection of magnesium sulfate in water,

d Based on rejection of sodium chloride in water,

e Based on rejection of polyethylene glycol in water,

$g$ Based on rejection of sucrose in water, 
Table 2 - Difference of measured and extrapolated osmotic pressure (bar) of permeates $\left(\Pi_{\text {per }}\right)$ and retentate $\left(\Pi_{\text {ret }}\right)$ at applied pressure 40 bar.

\begin{tabular}{lcccc}
\hline $\begin{array}{l}\text { Concentration } \\
\left(\mathrm{kg} \mathrm{m}^{-3}\right)\end{array}$ & $\begin{array}{c}\prod_{\text {ret }} \\
(\mathrm{bar})\end{array}$ & $\begin{array}{c}\Pi_{\mathrm{per}} \\
(\mathrm{bar})\end{array}$ & $\begin{array}{c}\Delta \Pi_{0}=\left(\Pi_{\mathrm{ret}}-\Pi_{\mathrm{per}}\right) \\
(\mathrm{bar})\end{array}$ & $\begin{array}{c}\sigma \Delta \Pi_{0} \\
(\mathrm{bar}) \\
\text { Extrapolated * }\end{array}$ \\
\hline 0.3 & 0.169 & 0.026 & 0.143 & 0.13 \\
0.9 & 0.497 & 0.016 & 0.481 & 0.42 \\
2.7 & 1.415 & 0.024 & & 1.391 \\
\hline
\end{tabular}

* $\sigma \Delta \prod_{0}$ obtained from the $x$-intercept of permeate flux $J_{\mathrm{v}}$ with applied pressure in Fig. 6. 
Table 3 - Osmotic pressure $\left(\Pi_{\mathrm{m}}\right)$, oleuropein membrane surface concentration $\left(C_{\mathrm{m}}\right)\left(\mathrm{kg} \mathrm{m}^{-3}\right)$ and concentration polarization modulus $(C P M)$, for different initial concentration of oleuropein.

\begin{tabular}{|c|c|c|c|c|c|c|c|c|c|c|c|c|}
\hline \multirow{3}{*}{$\Delta \mathrm{P}($ bar $)$} & \multicolumn{12}{|c|}{ Initial concentration $C_{0}\left(\mathrm{~kg} \mathrm{~m}^{-3}\right)$} \\
\hline & \multicolumn{4}{|c|}{0.3} & \multicolumn{4}{|c|}{0.9} & \multicolumn{4}{|c|}{2.7} \\
\hline & $\begin{array}{c}\sigma \Delta \Pi_{\mathrm{m}} \\
\text { (bar) }\end{array}$ & $\begin{array}{c}C P M= \\
\Delta \Pi_{\mathrm{m}} / \Delta \Pi_{0}\end{array}$ & $\begin{array}{c}\Pi_{\mathrm{m}} \\
\text { (bar) }\end{array}$ & $\begin{array}{c}C_{\mathrm{m}} \\
\left(\mathrm{kg} \mathrm{m}^{-3}\right)\end{array}$ & $\begin{array}{c}\sigma \Delta \prod_{\mathrm{m}} \\
\text { (bar) }\end{array}$ & $\begin{array}{c}C P M= \\
\Delta \Pi_{\mathrm{m}} / \Delta \Pi_{0}\end{array}$ & $\begin{array}{c}\Pi_{\mathrm{m}} \\
\text { (bar) }\end{array}$ & $\begin{array}{c}C_{\mathrm{m}} \\
\left(\mathrm{kg} \mathrm{m}^{-3}\right)\end{array}$ & $\begin{array}{c}\sigma \Delta \Pi_{\mathrm{m}} \\
\text { (bar) }\end{array}$ & $\begin{array}{c}C P M= \\
\Delta \Pi_{\mathrm{m}} / \Delta \Pi_{0}\end{array}$ & $\begin{array}{l}\Pi_{\mathrm{m}} \\
\text { (bar) }\end{array}$ & $\begin{array}{c}C_{\mathrm{m}} \\
\left(\mathrm{kg} \mathrm{m}^{-3}\right)\end{array}$ \\
\hline 5 & 0.27 & 2.06 & 0.20 & 0.36 & 0.43 & 1.03 & 0.20 & 1.01 & 0.48 & 1.04 & 0.51 & 2.89 \\
\hline 10 & 0.38 & 2.94 & 0.40 & 0.46 & 0.54 & 1.28 & 0.60 & 1.33 & 0.77 & 1.67 & 0.82 & 3.79 \\
\hline 20 & 0.92 & 7.06 & 1.0 & 0.54 & 0.99 & 2.36 & 1.10 & 1.56 & 1.09 & 2.37 & 1.22 & 4.62 \\
\hline 30 & 1.57 & 12.08 & 1.70 & 0.62 & 1.67 & 3.97 & 1.80 & 1.80 & 1.69 & 3.68 & 1.82 & 5.32 \\
\hline 40 & 2.31 & 17.75 & 2.50 & 0.71 & 2.38 & 5.67 & 2.70 & 2.12 & 2.41 & 5.25 & 2.30 & 6.36 \\
\hline
\end{tabular}


Table 4 - Calculated errors between experimental and calculated observed rejection values as function of permeate flux $\left(J_{\mathrm{v}}\right)$ for different initial concentration of oleuropein.

\begin{tabular}{|c|c|c|c|c|c|c|c|}
\hline \multirow{4}{*}{$\begin{array}{l}\text { Permeate flux, } J_{\mathrm{v}} \\
\left(10^{-6} \mathrm{~m}^{3} \mathrm{~m}^{2} \mathrm{~s}^{-1}\right)\end{array}$} & \multicolumn{7}{|c|}{ Initial concentration $C_{0}\left(\mathrm{~kg} \mathrm{~m}^{-3}\right)$} \\
\hline & \multicolumn{3}{|c|}{0.3} & \multicolumn{2}{|c|}{0.9} & \multicolumn{2}{|c|}{2.7} \\
\hline & $R_{\text {obs }}$ & $R_{\mathrm{obs}}$ & Error & $R_{\text {obs }}$ & Error & $R_{\mathrm{obs}}$ & Error \\
\hline & (predi.) & (exp.) & $(\%)$ & (predi.) & $(\%)$ & (predi.) & $(\%)$ \\
\hline 1.64 & 0.956 & 0.954 & 0.169 & 0.957 & 0.274 & 0.95705 & 0.279 \\
\hline 2.04 & 0.9518 & 0.952 & -0.068 & 0.955 & 0.267 & 0.957 & 0.476 \\
\hline 2.63 & 0.95 & 0.950 & 0.045 & 0.954 & 0.464 & 0.956 & 0.672 \\
\hline 3.13 & 0.946 & 0.947 & -0.085 & 0.951 & 0.442 & 0.953 & 0.650 \\
\hline 3.73 & 0.941 & 0.943 & -0.241 & 0.947 & 0.394 & 0.951 & 0.813 \\
\hline 4.03 & 0.938 & 0.941 & -0.364 & 0.945 & 0.380 & 0.949 & 0.799 \\
\hline 4.22 & 0.935 & 0.940 & -0.551 & 0.942 & 0.197 & 0.947 & 0.724 \\
\hline 4.33 & 0.934 & 0.940 & -0.589 & 0.9405 & 0.106 & 0.946 & 0.687 \\
\hline
\end{tabular}




\section{Figure captions}

Fig. 1. Chemical structure of oleuropein.

Fig. 2. Schematic representation of the experiment setup.

Fig. 3. Diagram of mass concentration distribution across an NF membrane (assume a single-layer membrane and steady-state concentration profile).

Fig. 4. Flat sheet membrane tested performances.

Fig. 5. Scheme of silicone network composed of PDMS polymer material (Stafie et al., 2005)

Fig. 6. NF permeate flux of oleuropein versus applied pressure.

Fig. 7. $\ln \left(C_{\mathrm{m}}-C_{\mathrm{p}} / C_{\text {ret }}-C_{\mathrm{p}}\right)$ versus the permeate flux of oleuropein solution.

Fig. 8. Schematic representation to obtain the solute permeability coefficient $(\omega)$ and the reflection coefficient $(\sigma)$ for $\mathrm{VRF}=1.05$ at $\Delta \mathrm{P}=25$ bars and stirring rate of $500 \mathrm{rpm}$ at different initial concentrations $\left(C_{0}=0.3\right.$ to $\left.2.7 \mathrm{~kg} \mathrm{~m}^{-3}\right)$.

Fig. 9 Comparison of flux decline due to osmotic pressure for oleuropein model solution.

Fig. 10. Predictive evolution of oleuropein rejection with permeation flux and Peclet number for MPF44 membrane (oleuropein concentration $2.7 \mathrm{~kg} \mathrm{~m}^{-3}$ ). The curve of $R_{\text {int }}$ was fitted using the Spiegler-Kedem model, and that of $R_{\mathrm{obs}}$ was fitted using the film relationship. 
<smiles>C/C=C1/[C@H](CC(=O)OCCc2ccc(O)c(O)c2)C(C(=O)OC)=CO[C@@H]1O[C@@H]1O[C@H](CO)[C@@H](O)[C@H](O)[C@H]1O</smiles>

Oleuropein $\left(\mathrm{C}_{25} \mathrm{H}_{32} \mathrm{O}_{13}\right)$

\section{Fig. 1}

Oleuropein $\left(\mathrm{C}_{25} \mathrm{H}_{32} \mathrm{O}_{13}\right)$ 
Fig. 2

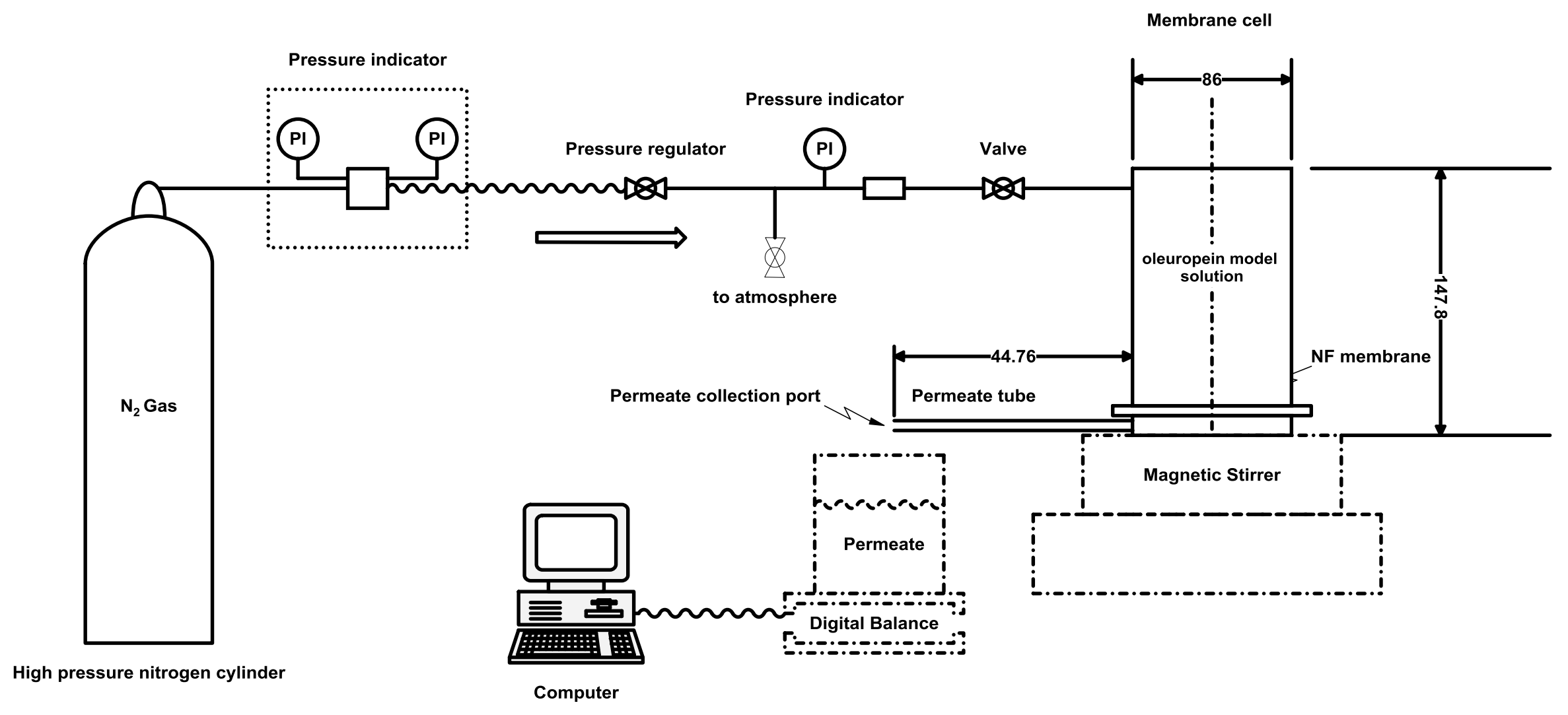


Fig. 3

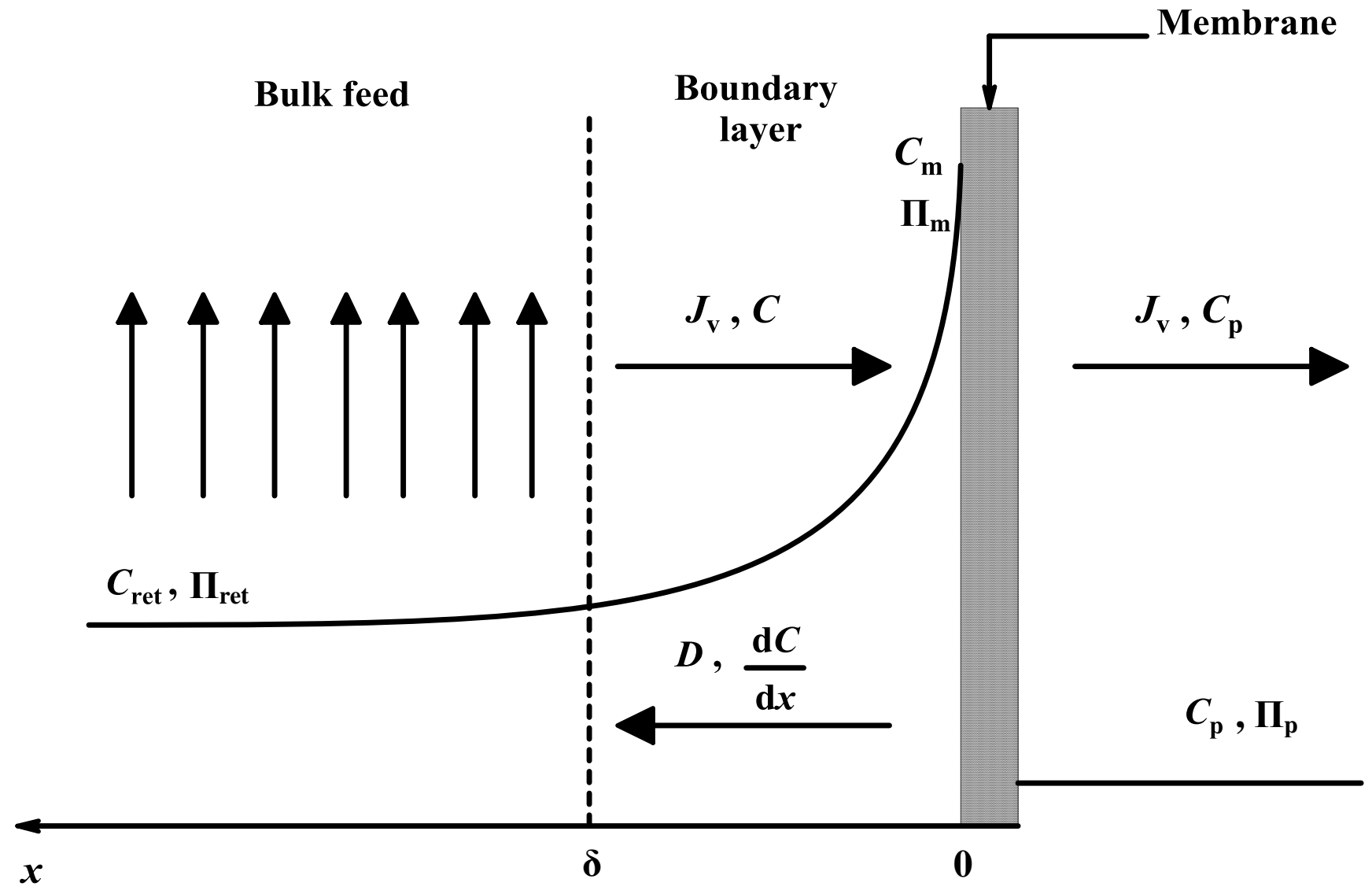


Fig. 4

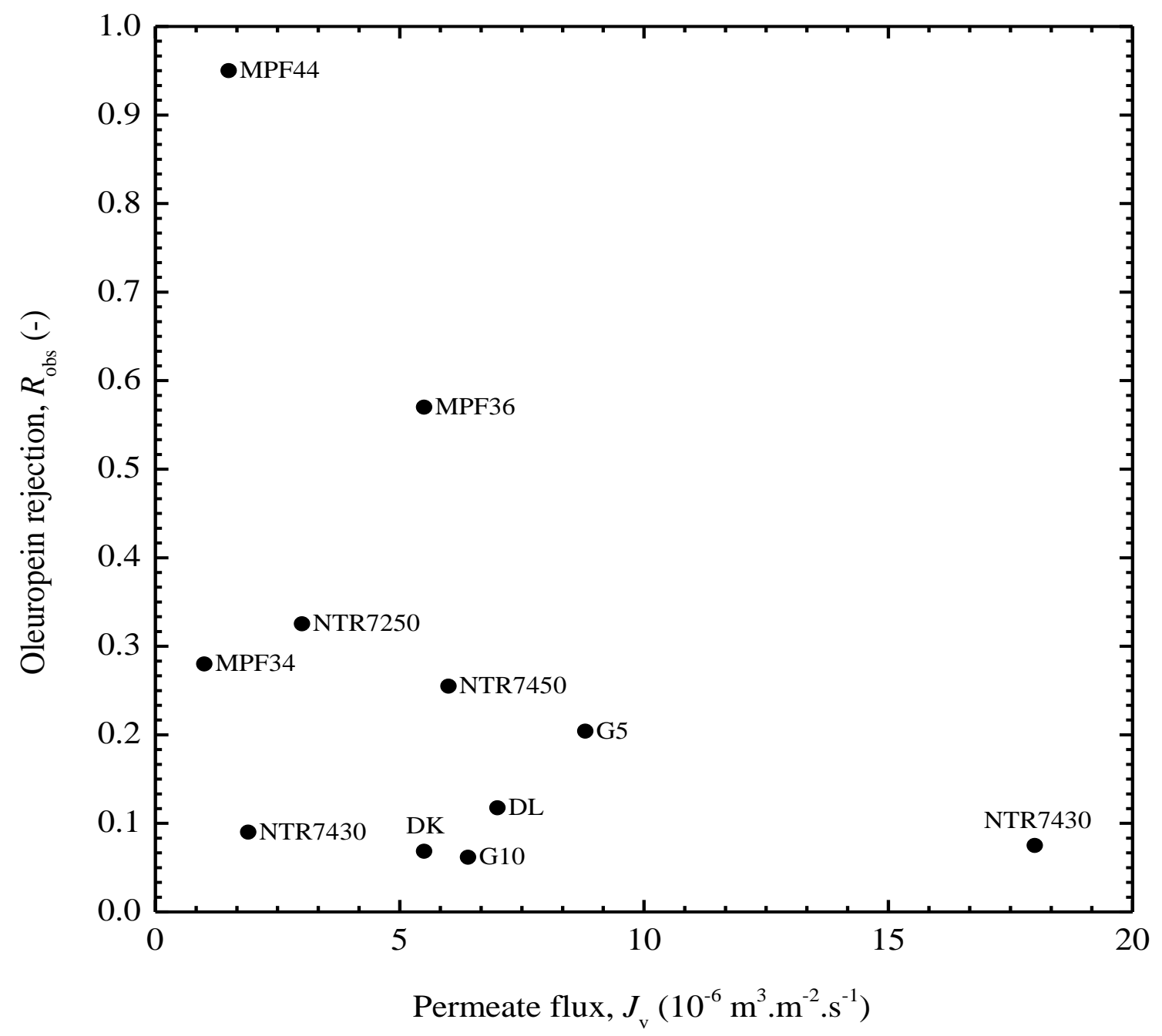


Fig. 5

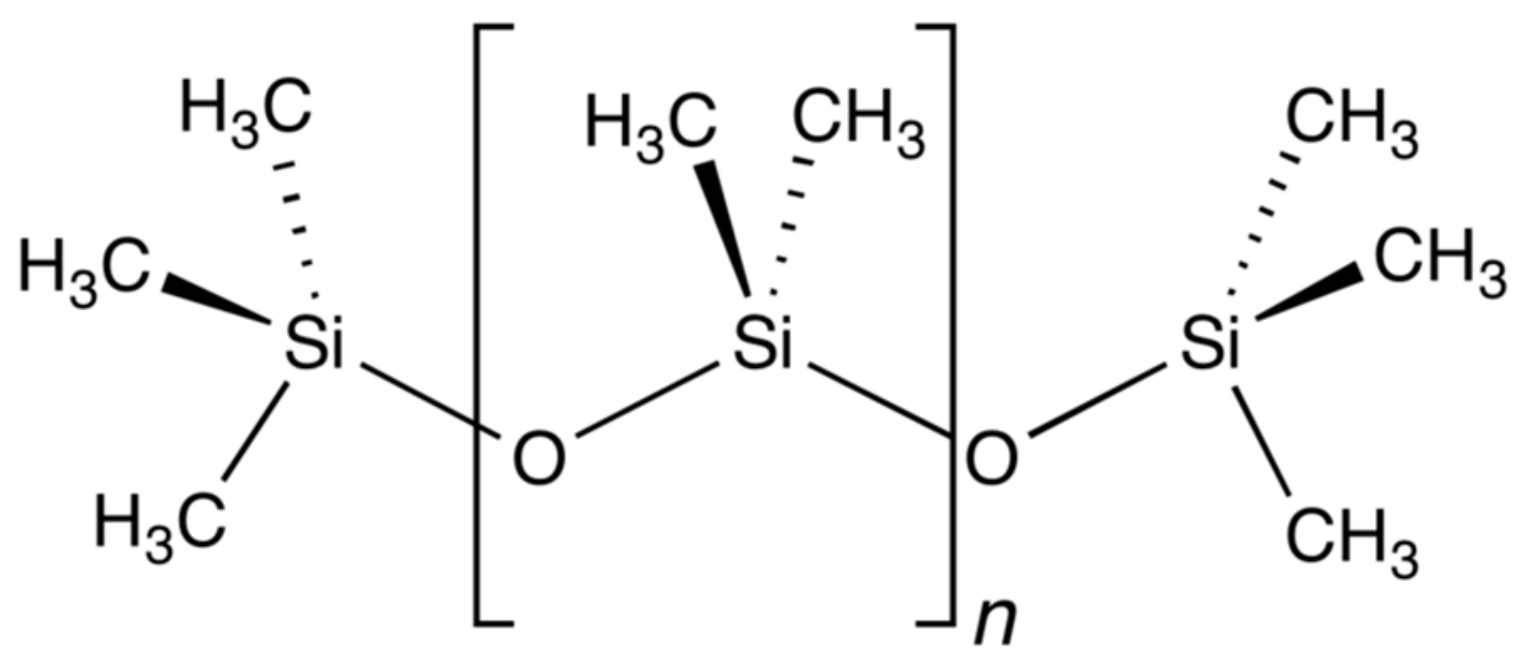


Fig. 6

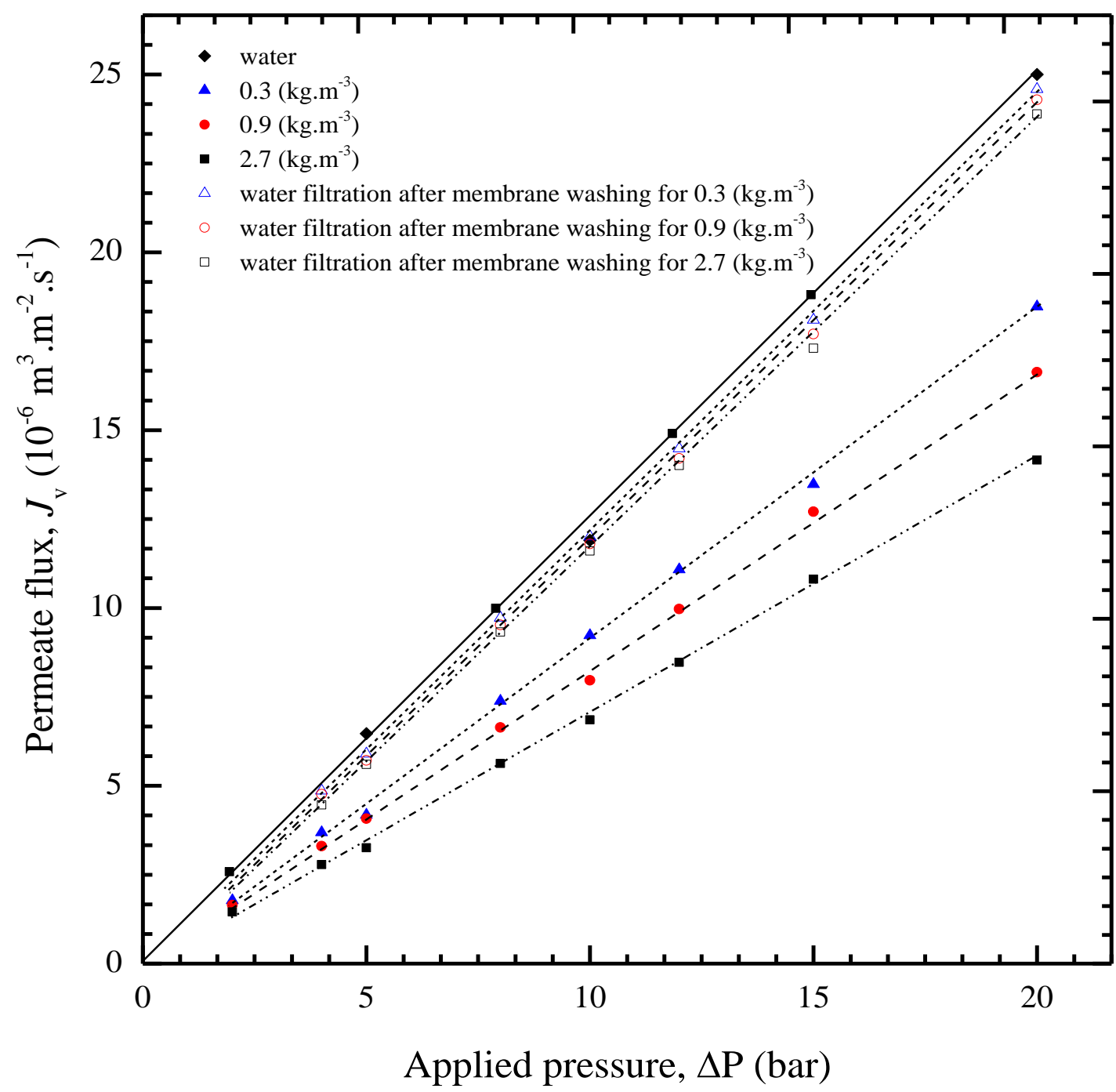


Fig. 7

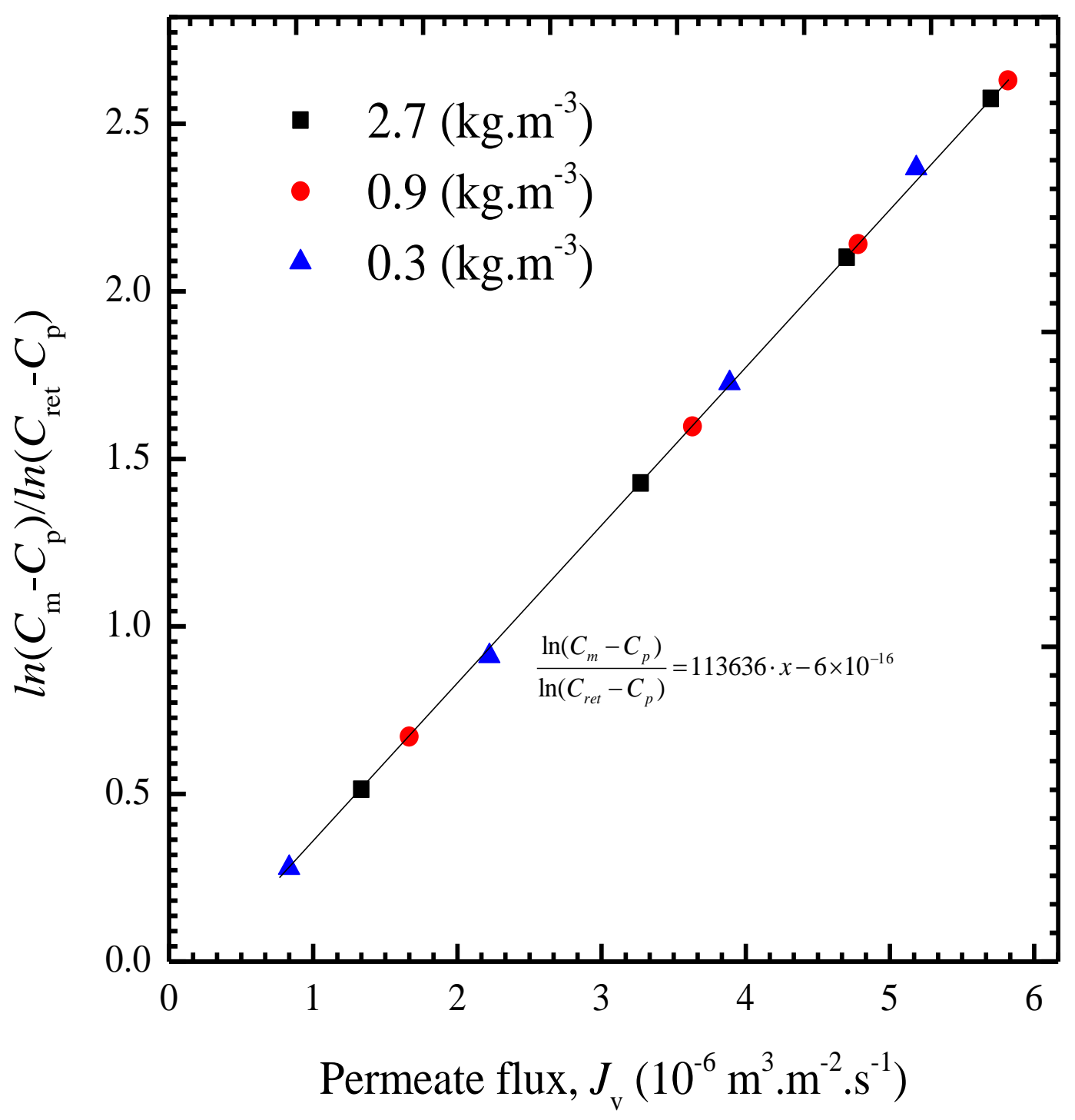


Fig. 8

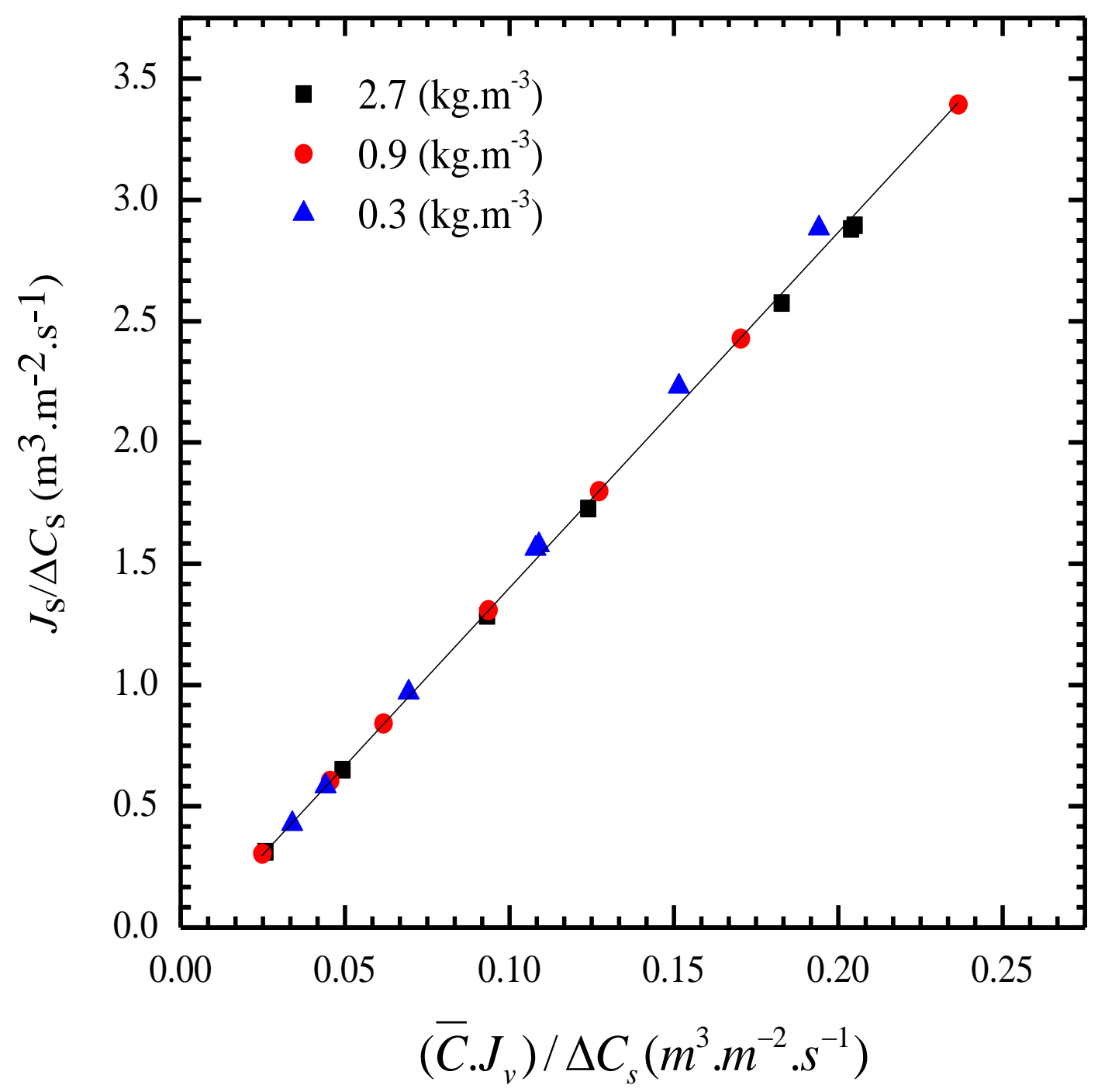


Fig. 9

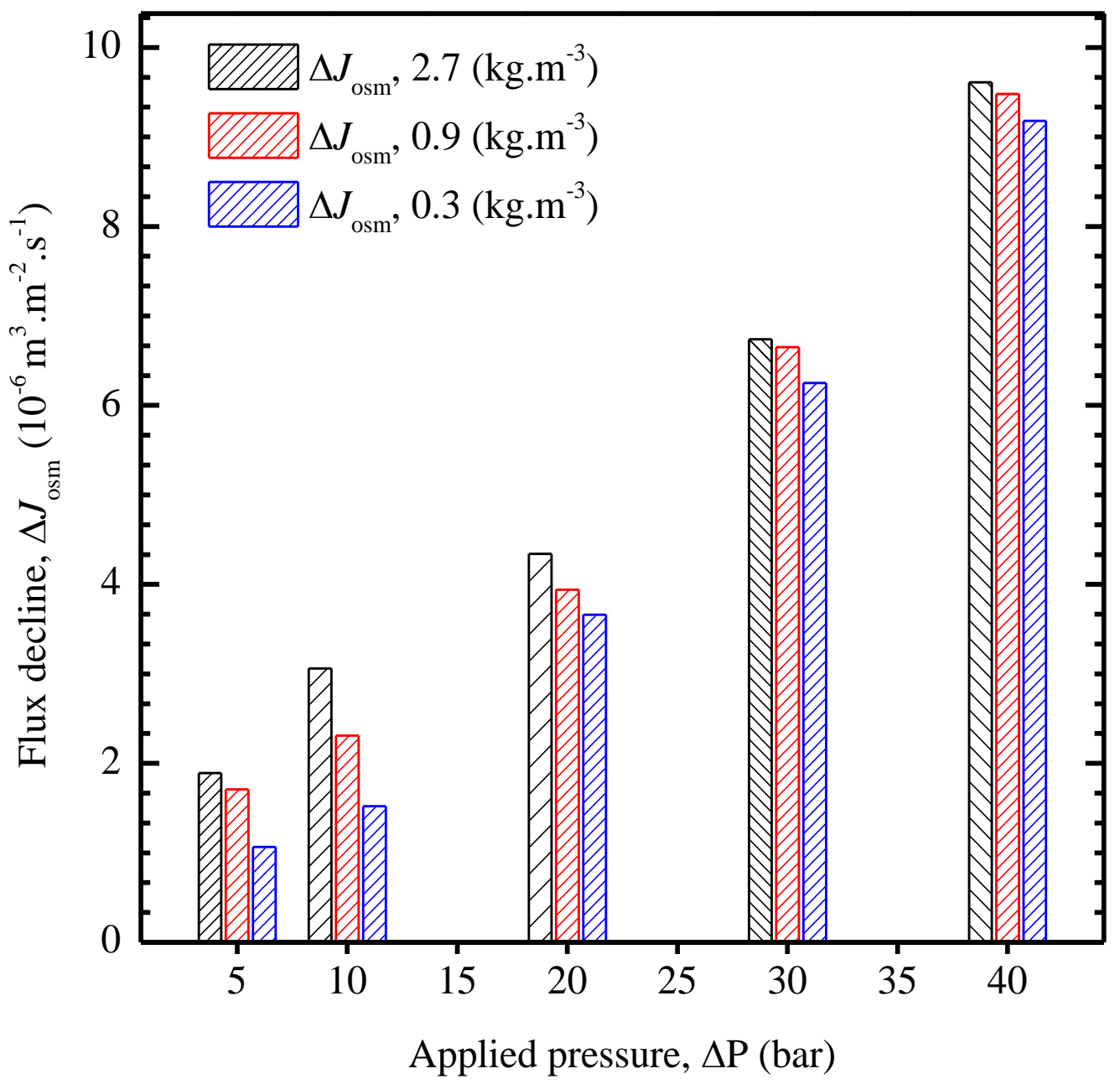


Fig. 10

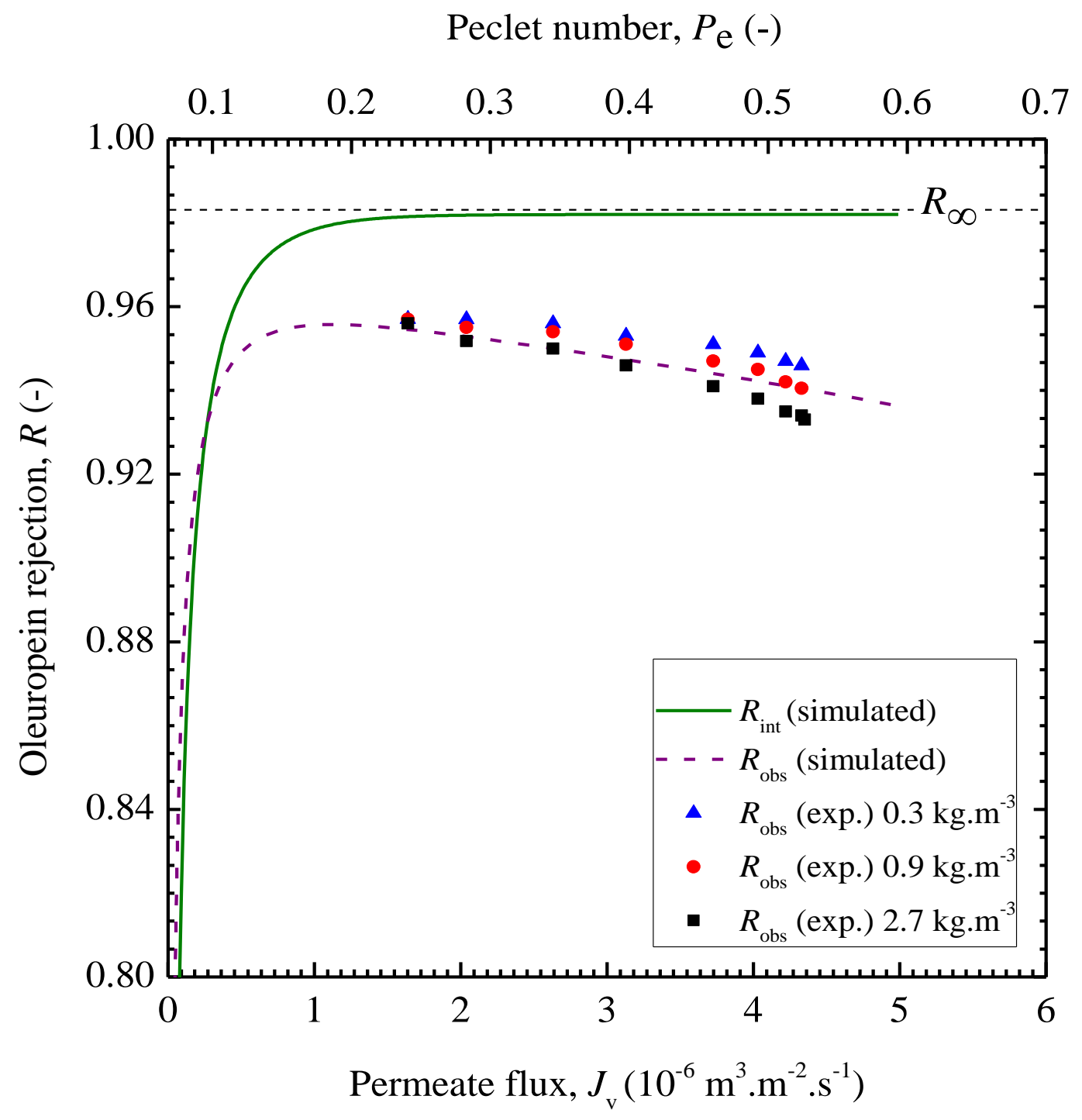


Simulation of NF membrane performance using transport parameters $R_{\text {obs }} \quad$ : observed rejection of oleuropein [-]

$R_{\text {int }} \quad:$ intrinsic rejection of oeluropein [-]

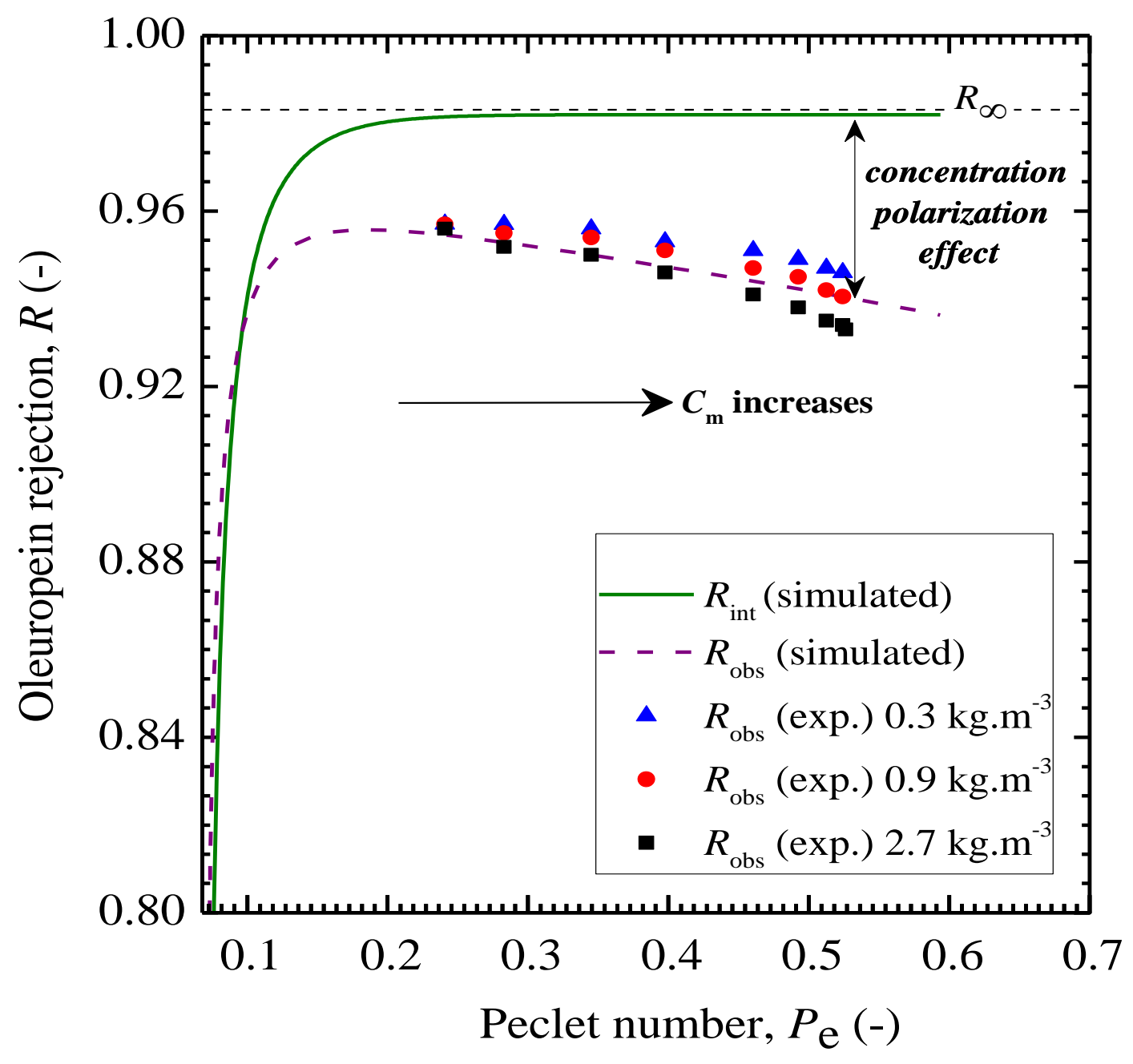

